\title{
Artistic Creation and Intellectual Property: A Professional Career Approach ${ }^{1}$
}

\author{
Francisco Alcalá ${ }^{2}$ and Miguel González-Maestre ${ }^{3}$
}

April 2011

${ }^{1}$ We thank Luis Corchón, Matthew Ellman, two referees and a coeditor of the JEMS for very useful comments and suggestions. We also gratefully acknowledge financial support from the Spanish Ministry of Education and Science project ECO2008-02654/ECON and from the Fundación Séneca de la Región de Murcia project 11885/PHCS/09. Francisco Alcalá also thanks the hospitality of the Economics Department at NYU, which he visited while conducting part of this project.

${ }^{2}$ Universidad de Murcia and Ivie. E-mail: alcala.paco@gmail.com

${ }^{3}$ Universidad de Murcia. Departamento de Fundamentos del Análisis Económico, Campus de Espinardo, 30100 Murcia, Spain. E-mail: mmaestre@um.es. 


\begin{abstract}
Reaching high levels of artistic creation in a society requires institutions that facilitate the sorting of the most talented individuals of each generation and the development of their skills across artistic careers. The impact of long copyrights is not straightforward in this respect. This paper takes a professional career approach to analyzing how copyright regulation affects artistic creation. It does so within an overlapping-generations model of artists. Long copyrights increase superstar market concentration and can reduce the number of young artists being able to pursue artistic careers. As a result, in the long run, excessively long copyrights can reduce artistic creation, the average talent of artists, and social welfare.
\end{abstract}

Keywords: copyrights, superstars, sorting of talent, artistic markets.

JEL Classification: J44, L82, O34. 


\section{Introduction}

New technologies and globalization are profoundly affecting artistic markets. Simultaneously, intellectual property is undergoing important regulation changes in many countries. For instance, the copyright term has been extended in the US from 50 to 70 years after the death of the creator, and the European Union is considering an extension of the copyright term from 50 to 90 years. These changes are taking place amid an ample debate on how copyrights should optimally be regulated. ${ }^{1}$

Most economic literature approaches the production of artistic ideas in the same way as the production of technological ideas. ${ }^{2}$ In doing so, it ignores several distinctive and prominent facts of artistic markets. Specifically, it does not take into account that $(i)$ artistic markets are superstar markets (Rosen, 1981), ${ }^{3}$ (ii) promotion and marketing expenditures are vast and play a central role in determining market shares, and (iii) artistic talent -which is a key ingredient in producing artistic ideas- is sorted out and developed through artistic careers that most often end in failure. These facts are likely to be relevant for the optimal regulation of intellectual property in artistic markets.

This paper provides a new approach to the analysis of the long-run link between copyright regulation and artistic creation. The approach is based on a professional career perspective of the determinants of artistic creation that embeds the three stylized facts cited above. Accounting for them provides new important insights. Long copyrights can outgrow superstars' market share and reduce the opportunities for young artists to begin an artistic career. As a result, in the long run, excessively long copyrights can reduce artistic creation, the average talent of senior artists, and social welfare.

Let us review each of those three facts. Several papers provide evidence of the huge differences in market share and earnings between a small number of superstars and the remainder of artists. For example, in the case of Rock and Roll, Krueger (2005) reports that the top 1\% of artists obtained $26 \%$ of concert revenue in 1982 . In 2003, this proportion increased to $56 \%$. Similarly, the top $5 \%$ of revenue generators took in $62 \%$ of concert revenue in 1982 and $84 \%$ in 2003. There is also evidence on the extremely skewed distribution of copyright yields across artists although data about earnings from copyrights are not easily accessible. Kretschmer and

\footnotetext{
${ }^{1}$ For example, the proposed extension of the copyright term in the European Union has been labeled as "a redistribution of income from living to dead artists" (Kretschmer et al., 2009). See Akerloff et al. (2002) and Liebowitz and Margolis (2003) for different positions on the optimality of the last extension of the copyright term in the US; Kretschmer et al. (2008) for the discussion of the proposed extension in the European Union; Grossman and Lai (2004) and Boldrin and Levine (2006) for a debate on how the copyright term should be changed as market size increases; Peitz and Waelbroeck (2005) and Varian (2005) for surveys; and The Economist October 11th 2007 and April 9th 2010 for accounts of the ongoing debate.

${ }^{2}$ See Landes and Posner (1989) for a list of references.

${ }^{3}$ Superstar markets are markets with a strong concentration of output and revenues for those few sellers who have the most talent. Sherwin Rosen (1981) showed that these markets are a natural outcome when goods are intensive in an innate input such as talent and there are scale economies arising from joint consumption.
} 
Hardwick (2007) report data on the distribution of payments in 1994 by the UK Performing Right Society. This society distributed $£ 20,350,000$ among 15,500 writers for the public performance and broadcasting of their works. The top $9.3 \%$ of writers earned $81.07 \%$ of the total. Ten composers earned more than $£ 100,000$, whereas $53.1 \%$ of the composers earned less than $£ 100$. The data for the Spanish artistic market show an even higher degree of concentration: the top $1.5 \%$ of beneficiaries of the main collecting society in the country, SGAE, obtain $75 \%$ of total revenues (AEVAL, 2008). ${ }^{4}$

The second cited fact about artistic markets is the important role played by vast promotion and marketing expenditures. As the International Federation of the Phonographic Industry (IFPI) puts it "Extraordinary talent is a pre-requisite for a commercially successful artist or band. Yet even for the most talented act, there is another factor that determines whether they will achieve acclaim or anonymity -and that is marketing." Marketing and promotion are often the biggest budget items for a record label taking an act to the public. According to IFPI (2010), the typical budget to promote a superstar runs about US $\$ 2.3$ million, and around $30 \%$ of the record companies' revenues are spent on artist development and marketing. Production, marketing, and promotion often are the main cost of making and selling a CD (Peitz and Waelbroeck, 2004) and are also huge and critical for success in the movie industry. ${ }^{5}$

The third stylized fact about artistic markets featured in this paper is that artistic talent is sorted out and developed through artistic careers. Typically, the process of sorting and developing innate individual abilities is carried out through the period of formal education. However, some abilities such as artistic talent and charisma cannot be ascertained without the individual actually performing the professional activity (Johnson, 1978). Young artists need time and some share of the market to develop their skills. The market (promotion firms and consumers) needs time to test and sort out the real talent (MacDonald 1988). This gives rise to a positive dynamic link between the number young artists that are able to initiate an artistic career in a given period and the number and average talent of senior artists in the next periods (though most of young artists will not succeed and will abandon the career). Thus, reaching high levels of artistic creation in a society requires institutions that facilitate the sorting of the most talented individuals of each generation and the development of their skills across artistic careers. ${ }^{6}$ Understanding the long-run consequences of copyright regulation for artistic creation

\footnotetext{
${ }^{4}$ Rothenbuhler and Dimmick (1982) and Crain and Tollison (2002), among others, provide additional evidence on the market concentration in artistic markets. For the motion picture industry, see Chisholm (2004) whose empirical work indicates that stars obtain substantial economic rents.

${ }^{5}$ For example, an average of marketing costs for a Motion Picture Association of America (MPAA) film in 2006 was $\$ 34.5$ million (Young et. al, 2008). Likewise, according to C. Eller who cites the movie trade association as the source, worldwide marketing budgets in 2009 were topping $\$ 100$ million for each of the biggest-budget movies (see Los Angeles Times, April 20th 2009; available at http://articles.latimes.com/2009/apr/20/business/fi-ctmovies20)

${ }^{6}$ Scherer (2006) provides some interesting historical evidence on the link between the existing opportunities to test talent and the effective development of talent. Relative to its population, the country that historically is the most intensive employer of composer-musicians (Austria) is also the country having given birth to the largest
} 
requires understanding how this regulation affects young artists' incentives and opportunities for beginning an artistic career. ${ }^{7}$

Not infrequently, these three facts come up in informal discussions and blogs about music and copyrights. However, as already noted, they have not been integrated in a formal analysis, which is the goal of this paper. Our analysis is framed into an ovelapping-generations model of artists. First, we consider a model with only two types of artists (talented and not talented), which borrows important features from MacDonald (1988). Artists begin their careers as young artists whose talent is uncertain; only those that show talent after their first life-period continue the artistic career and become stars in their second (and last) life-period. Second, we generalize the results in a model with a continuum of talents. Although the mechanisms involved in these two models may seem different, the key condition for the main results is the same: the superstar effect must be important; i.e., a substantial share of market revenues accrues to a small fraction of superstars that obtain large rents. When this occurs, reinforcing copyrights increases superstars' marketing expenditures, rents and market share, but reduces young artists' opportunities to begin artistic careers. In the long run, this is negative for artistic creation. Moreover, if artistic variety is sufficiently valuable to consumers, this also reduces social welfare.

The result that stronger copyrights can reduce artistic creation in the long run is in contrast to the standard analysis of intellectual property. According to the standard analysis, the copyright regulation problem is to find an optimal compromise between the (always) positive effect that stronger copyrights have on artistic creation and their negative underutilization effect (see Hirshleifer and Riley (1979), Novos and Waldman (1984), and the references therein). An exception is Landes and Posner (1989), who point out that excessively strong intellectual property rights may in fact hinder the development of new ideas that are based on previous ones. However, this last paper also ignores the dynamic effects of copyright regulation on the expected value of artistic careers and does not account for the three cited characteristics of artistic markets that are central to our approach.

The paper is organized as follows. In Section 2 and 3 we consider a model with two types of artists in terms of talent. We analyze the long-run consequences for artistic creation and social welfare of changes in the copyright term and progress in technologies that favor market concentration. In Section 4, we build a model with a continuum of artist types. In addition to generalizing the previous results, this model provides new insights on how, in the long run, copyright regulation influences the average talent of senior artists. We summarize and conclude in Section 5. The appendixes provide further generalizations and analytical details.

number of successful composers.

${ }^{7}$ The need for a professional career approach in the analysis of the allocation of human resources is also important in some other markets. For example, having a large supply of good politicians and large-firm managers not only depends on paying them large sums at the peak of their careers but on developing the appropriate institutions and environment such that new potential talent can be tested, sorted, trained, and promoted. Market failure arises as a consequence of the impossibility of insuring against the uncertainties of the professional career. See Terviö (2009). 


\section{The Model with Two Artist Types}

Consider an economy with overlapping generations of potential artists who live for two periods. Every period, each potential artist may decide to be active as an artist, in which case she creates a single artistic good (such as a song, novel, or movie). Alternatively, if she decides to stay out of the artistic market, she earns an income $F^{Y}$. Artistic goods are made available to consumers by means of copies, which are produced at a constant marginal cost $c .{ }^{8}$ Talent is heterogeneous. Specifically, artists may be either talented or not talented. However, their type is unknown to the public as well as to the artists themselves before they begin their artistic careers. There is free entry to the artistic market as an unknown artist.

In this environment, MacDonald (1988) has analyzed how artists are sorted by the market through an information accumulation process. Assuming that future performance is correlated with past performance, MacDonald shows that individuals will enter an artistic career only when young (i.e., the first life-period), and remain in the artistic market for the second period only if they receive a good review of their performance in the first period. If this happens, their performances in their second life-period are attended by a larger number of consumers who pay higher prices (i.e., they become superstars). In this paper we take advantage of these results to simplify some aspects of the model and concentrate on the consequences of the legal and economic environment for the long-run dynamics of artistic creation.

Following McDonald's (1988) results, we proceed to assume that individuals entering the artistic profession do so in their first life-period. When entering the artistic market, they become young artists and create an artistic good. Only a fraction $\rho$ of young artists are talented, but neither them nor artistic firms or the public can observe this innate characteristic until after the artist has completed her first life-period. At the end of this first period, the fraction $\rho$ of talented young artists reveal their talent and decide whether to continue the artistic career in the second life-period. In turn, the fraction $1-\rho$ of young artists that are revealed to be non-talented do not find it profitable to remain in the artistic market. Talented artists that continue the artistic career in the second period are called senior artists or stars. ${ }^{9}$ Each of these senior artists creates a high-quality artistic good in her second life-period. Thus, per period high-quality artistic creation is equal to the number of active senior artists.

\footnotetext{
${ }^{8}$ In this paper, all copies are assumed to be produced and sold by the owner of the copyright in the case that the copyright has not yet expired. Thus, we do not consider piracy and file sharing. On these issues, see Alcalá and González-Maestre (2010). There, we explore the consequences of unauthorized copying and levies on copy equipment in a model in which artistic firms use limit pricing strategies and consumers are heterogeneous in terms of their preferences for irregular copies and originals.

${ }^{9}$ Note also that in this paper we consider each artist and her possible promotion and managing firm as a single unit. Thus, we ignore the potential bargaining problems and conflicts of interest between artists and promotion firms, which have been analyzed elsewhere. See, for example, Gayer and Shy (2006).
} 


\subsection{The Artistic Career: Expected Utility and Constraints}

Potential young artists maximize lifelong expected utility $U\left(c_{1}, c_{2}\right)=\frac{1}{1-\sigma} c_{1}{ }^{1-\sigma}+\frac{\theta}{1-\sigma} E\left[c_{2}{ }^{1-\sigma}\right]$, where $c_{1}$ and $c_{2}$ are consumption at each life-period, $\sigma>0$ is the constant relative risk-aversion coefficient, and $\theta<1$ is their intertemporal discount factor. They compare the expected utility of starting and not starting an artistic career. In line with the analysis in Terviö (2009), we assume that young artists cannot borrow against their future expected income and, in particular, against the revenues that they would obtain in the unlikely event that they become stars. As already indicated, we denote by $F^{Y}$ the per-period income earned by any individual outside the artistic market. Thus, the expected utility in the case of not starting an artistic career is $\frac{1+\theta}{1-\sigma}\left(F^{Y}\right)^{1-\sigma}$. Alternatively, the expected utility of starting an artistic career is:

$$
\frac{1}{1-\sigma}\left(\pi_{t}^{Y}\right)^{1-\sigma}+\frac{\theta}{1-\sigma}\left[\frac{n_{t+1}}{m_{t}}\left(\pi_{t+1}^{S}\right)^{1-\sigma}+\left(1-\frac{n_{t+1}}{m_{t}}\right)\left(F^{Y}\right)^{1-\sigma}\right]
$$

where $\pi_{t}^{Y}$ is earnings of a young artist at time $t, \pi_{t}^{S}$ is earnings of a senior artist, $m_{t}$ is the number of young artists at time $t$, and $n_{t+1}$ is the number of stars one period later $\left(n_{t+1} \leq m_{t}\right)$. Note that the probability of becoming a star is the same for all young artists at the moment of deciding whether to start an artistic career and is equal to the ratio $n_{t+1} / m_{t}$. Young artists that do not become stars after the first period drop out from the artistic market and earn $F^{Y}$ in the second period. Free entry to the artistic career implies that the expected utility of starting an artistic career must be equal to its opportunity cost:

$$
\left(\pi_{t}^{Y}\right)^{1-\sigma}+\theta \frac{n_{t+1}}{m_{t}}\left[\left(\pi_{t+1}^{S}\right)^{1-\sigma}-\left(F^{Y}\right)^{1-\sigma}\right]=\left(F^{Y}\right)^{1-\sigma} .
$$

Stars have opportunity costs $F^{S}, F^{S} \geq F^{Y}$. Stars may have higher opportunity costs than young artists as a result of two circumstances. First, an individual that reveals talent in her fist period may have better outside options in the second life-period (because artistic talent may be positively correlated with other skills that are valuable in non-artistic occupations). Second, to create high-quality artistic goods, it may be optimal to combine talented work with some other inputs that are more costly than those that are optimal to use by young artists when creating their art. These additional inputs can be thought as being included in the stars' opportunity cost $F^{S} \cdot{ }^{10}$

High-type artistic creation requires the stars' revenues to be at least as large as their opportunity costs: $\pi_{t}^{S} \geq F^{S}$. In equilibrium, this constraint may be slack; that is, stars may obtain economic rents. The reason is that there is not free entry to the artistic market as a star but the number of stars in a given period is limited by the number of talented young artists that entered the artistic market in the previous period. In fact, according to the evidence cited in

\footnotetext{
${ }^{10}$ The financial importance of these inputs may greatly vary across artistic activities. For example, they may have a large weight in the cost of producing high-quality movies, whereas writing novels may involve little more than the writers' time. Still, we do not carry out an explicit analysis on the possible complementarities between talented artistic work and other inputs because this would add little to the analysis but some tedious algebra.
} 
the Introduction, stars do seem to obtain large rents. Hence, we assume throughout Sections 2 and 3 that $\pi_{t}^{S}>F^{S}$. Then, all the young artists that show talent in a given period will be willing to continue their careers as stars the next period:

$$
n_{t}=\rho m_{t-1}
$$

In Appendix A we also consider and discuss the case in which $\pi_{t}^{S} \geq F^{S}$ is binding, in which case we may have $n_{t}<\rho m_{t-1}$.

\subsection{Demand and Competition in Artistic Markets}

There is a continuum of consumers $Z$ each one buying a copy of an artistic work each period. There are two artistic sub-markets: the stars' and the young artists' submarket. Horizontal differentiation within each artistic sub-market is modeled following Salop (1979). That is, consumers are uniformly distributed in each sub-market along a circular space of preferences that has a length of one unit. Artists competing in each sub-market are located symmetrically around that circle. The consumer buying from artist $i$, who is located at a distance $z$, obtains utility

$$
U\left(Q_{i} ; p_{i} ; z\right)=Q_{i}-p_{i}-\lambda z
$$

where $Q_{i}$ is the quality of artist $i$ 's creation, $p_{i}$ is its price, and $\lambda$ is the consumer unit transport cost, which can be interpreted as the disutility associated with departing from her optimal consumption location. We assume that $Q_{i}$ is the same for all of the artists in the same submarket and that $Q^{S} \geq Q^{Y}$; where $Q^{S}$ and $Q^{Y}$ are respectively the expected quality of stars' and young artists' work. To simplify the analysis we also assume that $Q^{S}$ and $Q^{Y}$ are sufficiently large to ensure that in equilibrium all the consumers buy one copy of an artistic good.

The fraction of consumers buying superstars' work is denoted by $a$ (thus, $(1-a)$ is the fraction buying young artists' work). The fraction $a$ depends on stars' advertising and marketing expenditures as follows. There is an open debate as to whether advertising is informative or merely persuasive, and as to whether it is necessary to be more talented in order to become a star. ${ }^{11}$ Our setting can be interpreted in several ways in this respect. In this main text, we consider the interpretation that makes the strongest case, from the social welfare viewpoint, in favor of a large stars' market share. We assume that $Q^{S}$ is not only strictly higher than $Q^{Y}$ but the difference is sufficiently large such that any consumer would buy a senior artist's work instead of a young artist's work (independently of their location in the circular space of characteristics) if the consumer were informed about which the talented senior artists' creations are. Furthermore, stars' advertising and marketing is the mechanism informing the consumers about which the senior artists' creations are. Thus, stars' advertising increases the fraction $a$ of

\footnotetext{
${ }^{11}$ See Adler (1985) for a theoretical contribution on how artists can become superstar without special talent, and Hamlen (1991) and Spierdijk and Voorneveld (2009) for empirical tests and references to additional analyses.
} 
consumers that are informed and therefore buy from the stars' sub-market. ${ }^{12}$

These circumstances are captured in a simple form by expression (4) below. This particular expression entails some simplifying assumptions that allow for an explicit solution of the equilibrium number of artists. The analysis is generalized in this respect in Appendix C. Denote total stars' advertising and marketing expenditures as $A \equiv \sum_{i=1}^{n} A_{i}$, where $A_{i} \geq 0$ is the star $i$ 's marketing expenditure. Aggregate stars' market share $a$ depends on their marketing expenditures according to the following expression:

$$
a=1-\beta e^{-\gamma n A / Z}
$$

where $n$ is the number of senior artists $(n \geq 2)$ and $\beta$ and $\gamma$ are exogenous parameters $(1>\beta>0$, $\gamma>1$ ). Thus, the stars' market share would be equal to 1 if $A=\infty$ and equal to $1-\beta$ if $A=0$. Note that the advertising expenditures that are necessary to obtain a given market share are proportional to market size $Z$. This is consistent with the idea that informing more consumers about stars' work requires larger advertising expenditure. ${ }^{13}$

The parameter $\gamma$ in expression (4) determines how productive advertising expenditure is in gaining market share. This parameter may be thought to depend on the state of communication and reproduction technologies, the potential market that stars can reach, and the barriers to the globalization of culture. ${ }^{14}$ Comparative statics with respect to parameter $\gamma$ will allow us to analyze the consequences for artistic creation of changes in these circumstances that favor stars' market share. ${ }^{15}$

\footnotetext{
${ }^{12}$ In the case $Q^{S}=Q^{Y}$ or if some consumers always prefer young artists' work then the model would deliver stronger results in favor of a short copyright and a small stars' market share. In such a case $Q^{S}=Q^{Y}$, stars' advertising has to be interpreted as being persuasive (instead of informative), pushing a fraction $a$ of consumers to buy star creations even if they are not of higher quality.

${ }^{13}$ A firm's advertising tends to increase both the demand for that firm's good and the overall demand for the type of good being advertised. As a result, advertising increases the share of this type of good in consumers' expenditure (Sutton, 1991). In the formulation above we model advertising as a public good for stars, ignoring the competitive effects of advertising within stars and focusing on the aggregate interactions between young artists and star sub-markets. In Appendix C, we generalize the advertising function and also assume that each star's expenditure in advertising has an individual effect on the perceived quality of her specific work in addition to the positive effect on the stars' aggregate market share. We show that these generalizations do not change our qualitative results. Moreover, in that appendix we show that the assumption that young artists do not advertise is not necessary but can be obtained as an equilibrium result.

${ }^{14}$ For example, when Alfred Marshall was calling attention to the superstar phenomenon for the first time, the maximum audience that an opera superstar could reach was limited by the size of theatres. Now, a singer can potentially reach a worldwide audience at any time.

${ }^{15}$ Note that we are implicitly assuming that stars marketing expenditures $A$ do not affect the total number of sales of artistic goods, $Z$. However, it could be argued that these expenditures may have a market expanding effect and therefore a positive effect on $Z$. Thus, if stars increase their marketing expenditures, the increase in their sales may come in part as a result of a shift in demand from young artists' work to stars' work and in part as a result of an increase in the overall consumer expenditure on artistic goods. However, there is no reason to expect that an increase in the stars' marketing expenditures would increase young artists' sales, which is the key assumption for our results.
} 
Within each period, we assume the following timing:

- Stage 1: Each young artist that revealed to be talented in the previous period decides whether to continue in the artistic market as a star.

- Stage 2: Each star chooses simultaneously and independently her marketing expenditure $A_{i}$.

- Stage 3: Potential new young artists decide whether to enter the artistic market.

- Stage 4: Each artist (young artists as well as stars) creates an artistic good and competes in prices with the rest of the artists in the same sub-market. At the end of this stage, talented young artists are revealed.

\section{Equilibrium}

In this section we analyze the equilibrium implications of the model assuming that young artists' intertemporal discount factor $\theta$ is zero. Under this strong assumption, the analysis delivers the main insights of the paper in the simplest possible way. In the last subsection we discuss the generalization of this analysis to the case $\theta>0$. The mathematics of this generalization are brought to Appendix A.

\subsection{Equilibrium with Short-lived Artistic Creations}

Before we introduce long-lived artistic creations and copyrights, the dynamics of the model are more easily presented by considering artistic creations that remain in the market for only one period.

The Short-Run Number of Young Artists Let us solve the equilibrium in a given period taking the number of stars $n$ as exogenous. Consider the Nash equilibrium (NE) at Stage 4. Following Salop's (1979) standard calculations, the price and output per artist in the stars' symmetric NE are $p^{S}=c+\lambda / n$ and $x^{S}=a Z / n .{ }^{16}$ Then we can solve for stage 2 . Stars' profit function can be written as

$$
\pi_{i}^{S}\left(A_{i}, A_{-i}\right)=\frac{\left(1-\beta e^{-\gamma n A / Z}\right) Z \lambda}{n^{2}}-A_{i}, i=1,2, \ldots, n
$$

\footnotetext{
${ }^{16}$ Consider artist $i$ 's marginal consumers, who are at distance $z_{i}$ one on each side of the artist's location. These consumers are indifferent between buying from $i$ or from their best alternative, who is at distance $1 / n-z_{i}$. These marginal consumers satisfy the following condition $p_{i}+\lambda z_{i}=p^{S}+\lambda\left(1 / n-z_{i}\right)$, where $p^{S}$ is the common price set by the other of artists at the symmetric NE of the price game. Thus, the demand function of artist $i$ is $x_{i}\left(p_{i}, p^{S}\right)=\frac{a Z}{\lambda}\left(p^{S}-p_{i}+\lambda / n\right)$. Artist $i$ 's first-order condition of profit maximization yields the expressions above after using the symmetry condition $p_{i}=p^{S}$.
} 
The first-order conditions for the NE of this second-stage game yield the equilibrium market share of stars $a(n)$ :

$$
\frac{\beta e^{-\gamma n A / Z}}{n}-1 /(\gamma \lambda)=0 \rightarrow a(n)=1-n /(\gamma \lambda)
$$

Note that $n<\beta \gamma \lambda$ is a necessary and sufficient condition for $A_{i}>0$ (which in turn guarantees $\pi_{i}^{S}>0$ ). This condition can always be met if $\gamma$ is large enough. Hence throughout the paper it is assumed that the effectiveness of promotion expenditures $\gamma$ is high enough for stars to be willing to spend a positive amount of money on promotion.

In turn, the NE in the young sub-market yields $p^{Y}=c+\lambda / m$ and $x^{Y}=(1-a) Z / m$. The equilibrium number of young artists $m(n)$ is then determined by the free entry condition (1), in which we substitute with $n_{t+1} / m_{t}=\rho$ according to expression (2). Assuming $\theta=0$, we have $\pi^{Y}=(1-a) Z \lambda / m^{2}=F^{Y}, i=1, \ldots, m$. Hence,

$$
m=\left(\frac{n Z}{\gamma F^{Y}}\right)^{\frac{1}{2}}
$$

The Long-Run Number of Artists Using (2) in the steady state to substitute in (7) yields the long-run equilibrium number of stars:

$$
n^{*}=\frac{\rho^{2}}{\gamma} \frac{Z}{F^{Y}} .
$$

Recall that changes in the parameter $\gamma$ can be seen as capturing positive effects on the stars' capacity to gain market share due to technological innovations, marketing improvements and reductions in cultural barriers. Historically, these changes have worked in favor of superstars. For example, theatre and live concerts in cities and small villages yielded their way to movies, TV shows, and recorded music in which superstars would thrive. More recent innovations, such as the Internet, may work in favor of the promotion and the diffusion of young artists work. ${ }^{17}$ Expression (8) shows that increases in $\gamma$ reduce the long-run number of stars $n^{*}$ (while raising stars' market share: see (6)). Moreover, a reduction in $n^{*}$ also implies a reduction in the long-run number of young artists because $n^{*}=\rho m^{*}$. Hence we have the following proposition.

Proposition 1 If stars obtain economic rents and young artists heavily discount the potential future revenues of becoming a star $(\theta=0)$, then technological and social innovations that favor stars' market concentration (as those captured by increases in $\gamma$ ) reduce artistic creation in the long run.

Intuitively, increases in stars' market share leaves little audience for young artists, thereby reducing its number. As a result, fewer new talents are discovered. This in turn reduces the number of talented artists and the amount of high-quality artistic creation in the long run.

\footnotetext{
${ }^{17}$ See for example Bar-Isaac, Caruana and Cuñat (2010).
} 


\subsection{Long-lived Creations and Copyrights}

We now explicitly introduce copyrights into the model. A central point in our argument is that young artist do not benefit as much as superstars from long copyrights. For instance, unsuccessful young artists stop receiving any royalties much before the 50 or more years that copyrights last in most developed countries. In a detailed analysis of depreciation of artistic originals, Soloveichik (2010b) finds that "depreciation schedules are not geometric. In the first year of life, artistic originals lose a substantial proportion of their value. After the first year, depreciation slows dramatically." In the case of music, she finds that only $13 \%$ of the albums sales occur more than one year after release and that very few albums sell any significant quantities more than five years after initial release (Soloveichik, 2010a). Thus, although original music may remain valuable for decades after it is first produced, this potential only materializes for a very small amount of great successes. These great successes are the only ones directly benefiting from long copyrights. ${ }^{18}$

These facts can be captured in a simple way by assuming in the model that young artists' works are sold only during the period in which they are created, whereas stars' works maintain positive (though decreasing) market shares after the period of creation. We assume that the market share of star creations from a given vintage decreases over time at a rate $\eta, 0<\eta<1$. Stars are assumed to be able to capture the present discounted value of the net yields from future sales by selling the copyright when they are still alive.

As before, there is a continuum of consumers $Z$ each buying one copy of an artistic good in each period. The fraction of consumers that buys contemporaneous artistic creations is $a_{0}(1-\eta)$; and, in general, a fraction $a_{\tau}(1-\eta) \eta^{\tau}$ of consumers buys creations from $\tau$ periods ago, $\tau=0, \ldots \infty$. Thus, $1-(1-\eta) \sum_{\tau=0}^{\infty} a_{\tau} \eta^{\tau}$ is the fraction of consumers that buy young artists' work in the current period. Furthermore, we have $a_{\tau}=1-\beta e^{-\gamma n A_{\tau} / Z}$, where $A_{\tau}$ is the amount spent in the promotion of senior artistic goods created $\tau$ periods ago (which was invested at the time of the good release, i.e., $\tau$ periods ago). We assume that $(1-\beta)(1-\eta) \geq 1 / 2$ to ensure that stars always fare better than young artists.

Consumers buying work from each vintage as well as those buying from young artists are distributed around a horizontal-differentiation circle with a length of one unit. Thus, the computation of prices and sales of stars' work from each vintage is analogous to the one in the previous subsections. That is, the current period NE price and sales per artist of work created

\footnotetext{
${ }^{18}$ Liebowitz (2007) provides some illustrative numbers on the decay of record sales in the UK by date of production. The percentage of albums sales in 2004 by year of production was: $60.9 \%$ albums of the 2000 s, $12.3 \%$ albums from the $1990 \mathrm{~s}, 11 \%$ from the $1980 \mathrm{~s}, 9.5 \%$ from the $1970 \mathrm{~s}, 4.8 \%$ from the $1960 \mathrm{~s}$, and $1.3 \%$ from the $1950 \mathrm{~s}$. This decay is not the same for unsuccessful young artists than for successful superstars. In fact, some superstars' work seems to have a decay rate close to zero. For instance, The Economist reports that America's bestselling album since 2000 is "1", a collection of Beatles hits from the 1960s. In the same vein, the number-one album in Britain at some point last year was a collection of songs by Vera Lynn who was then 92 years old (see the briefing on the music business in the October 9th 2010 issue). Kretschmer et al. (2008) provide evidence of the concentration of revenues from copyrights in a small percentage of successful artists.
} 
$\tau$ periods ago are $p_{\tau}^{S}=\frac{\lambda}{n_{\tau}}+c$ and $x_{\tau}^{S}=\frac{a_{\tau}(1-\eta) \eta^{\tau} Z}{n_{\tau}}$, where $n_{\tau}$ is the number of stars that were active $\tau$ periods ago. Then we can solve directly for the symmetric steady state equilibrium in which $n_{\tau}=n^{*}=\rho m_{t}=\rho m^{*}, A_{\tau}=A, a_{\tau}=a^{*}$. Each star's present discounted value of future revenues at the time in which she was active and decided on promotion expenditures $A_{i}$ is:

$$
\pi_{i}^{S}\left(A_{i}, A_{-i}\right)=\frac{1-\beta e^{-\gamma n A / Z}}{n^{2}} Z \lambda \omega(T)-A_{i} ;
$$

where $\omega(T) \equiv(1-\eta) \sum_{\tau=0}^{T-1}(\eta R)^{\tau}=(1-\eta) \frac{1-(\eta R)^{T}}{1-\eta R}, T \geq 1$ is the length of the copyright term, ${ }^{19}$ and $R<1$ is the general discount factor. ${ }^{20}$ Clearly, $\omega(T)$ is strictly increasing in $T$ and $R$ and is bounded by $1\left(\lim _{T \rightarrow \infty} \omega=1\right.$ if $\left.R=1\right)$. In the following, we take $\omega(T)$ as a continuously differentiable function of $T$. Moreover, to simplify the notation, we consider $\omega$ the copyright policy and refer to it as the length of the copyright term.

Maximizing (9) with respect to marketing expenditures and using symmetry yields the equilibrium values of $A$ and $a$ :

$$
A=\frac{Z}{\gamma n} \ln \left(\frac{\beta \gamma \lambda \omega}{n}\right), \quad a(n)=1-\frac{n}{\gamma \lambda} \frac{1}{\omega(T)} ;
$$

Below we give conditions guaranteeing $n<\beta \gamma \lambda \omega(T)$ in equilibrium, such that $A_{i}>0$. Substituting with (10) in (9) yields profits in equilibrium:

$$
\pi^{S}(\omega, n)=Z\left[\frac{\lambda \omega}{n^{2}}-\frac{1}{\gamma n}-\frac{1}{\gamma n^{2}} \ln \left(\frac{\beta \gamma \lambda \omega}{n}\right)\right] .
$$

In turn, the fraction of consumers buying young artists' work in the steady state is 1 $\sum_{\tau=0}^{\infty} a_{\tau}(1-\eta) \eta^{\tau}=1-a$. The NE in the young sub-market yields the same price and output per artist as in the previous subsections: $p^{Y}=\lambda / m+c, x^{Y}=(1-a) \lambda Z / m$. Hence, per capita young artists' revenues are again:

$$
\pi^{Y}=(1-a) Z \lambda / m^{2}
$$

Therefore, using the free entry condition, (2) and (10) yields the steady state number of senior and young artists:

$$
n^{*}=\rho m^{*}=\frac{1}{\omega} \frac{Z}{\gamma F^{Y}} \rho^{2}
$$

The following result is then immediate:

Proposition 2 If stars obtain rents and young artists heavily discount the potential future revenues of becoming a star, then extending the length of the copyright term reduces the long-run number of artists.

\footnotetext{
${ }^{19}$ In the model, copyrights need to exist for any art to be created at all. The assumption $T \geq 1$ means that the copyright term covers, at least, one period, which is the lifespan of young artists' creations.

${ }^{20}$ Note that young artists do not discount future revenues at the same rate that firms. They cannot borrow against the extremely uncertain income that they would obtain if they become stars. In contrast, the copyrights of successful star creations are actual assets that can be traded.
} 
Longer copyrights raise stars' revenues, but this does not necessarily help increase the number of artists. The reason is that, if stars obtain rents, then the constraint limiting the long-run number of talented artists is the number of young artists being able to pursue artistic careers. And the reason for this is that young artists' market share is too small. This reduces the possibility to discover new talent. Extensions of the copyright term increase stars' marketing expenditures and reduce young artists' market share even more. This chokes further the emergence of new talented artists.

\subsection{Social Welfare}

We just showed that stronger copyrights may lead to fewer artists and less creation. However, do fewer artists always imply lower social welfare? Not necessarily. In fact, it is well known that free entry may lead to an excessive number of firms in monopolistic competition markets (e.g., Salop, 1979). However, we show below that if artistic variety has a sufficiently large value for consumers or if talent is sufficiently scarce relative to artists' opportunity costs, then increasing the number of artists leads to higher social welfare. As a consequence, extensions of the copyright term that reduce the number of artists are negative for social welfare.

To show this, we consider the following expression for the per-period social welfare generated by the artistic market $(W)$ :

$$
W=\left[Q^{S} a Z+(1-a) Q^{Y} Z\right]-\left[a Z \frac{\lambda}{4 n}+(1-a) Z \frac{\lambda}{4 m}\right]-A-c Z-n F^{S}-m F^{Y}
$$

where the first term in square brackets is the consumers' gross utility obtained from buying artistic goods, the second term is the costs (or disutility) of distance between the artists' and the consumers' locations, and the remaining terms are advertising, production and artists' opportunity costs, respectively. The following result is proven in Appendix B:

Proposition 3 Assume that stars obtain rents and that the value of artistic diversity is sufficiently high (i.e., $\lambda$ large) or talent is sufficiently scarce (i.e., low $\rho$ ). Then, extending the length of the copyright term reduces social welfare in the long run.

To explain this result, note that there are four welfare effects associated with a longer copyright. First, the gross utility of consumers increases as stars' higher marketing expenditures raise the fraction of people consuming the star's output. This positive effect is conditional on stars' output being of higher quality than the other artists' output (i.e., $Q^{S}>Q^{Y}$ ). Second, distance costs increase (or equivalently, utility stemming from artistic variety decreases). This negative effect arises from the reduction in the number of both types of artists. Third, marketing costs $A$ increase. And fourth, total opportunity costs $n F^{S}+m F^{Y}$ are reduced as the number of artists decreases. If the value $\lambda$ of artistic variety is sufficiently high or the fraction $\rho$ of talented artist is sufficiently small, the second and third effects outweigh the first and forth effects. 
Note that the key novel mechanism in our analysis of the link between copyrights and welfare is the negative impact that excessively strong copyrights can have on the long-run number of artists, which was the result in the previous subsection. If the variety of high-quality artistic creation is small and sufficiently valuable, then the number of artists and social welfare move in the same direction: the negative effect of longer copyrights on the number of artists outweighs, from the point of view of social welfare, the positive effect of greater informative advertising and lower total opportunity costs.

There is another potential mechanism that increases the costs of excessively strong copyrights. This additional mechanism is the underutilization effect, which is the key effect limiting the optimal length of copyrights according to the standard analysis. It is due to the reduction in the use of already existing artistic goods that occurs if copyrights are extended. In our model, this effect is ignored because sales of artistic goods, $Z$, are constant and therefore inelastic to prices. However, extending the model to take into account the underutilization effect would reinforce the potential negative impact of long copyrights on social welfare.

\subsection{Generalizations}

The analysis can be generalized to the case in which young artists' intertemporal discount factor $\theta$ is strictly positive. In this subsection, we only state and discuss the results. The mathematics are worked out in Appendix A.

Stronger copyrights raise stars' potential revenues and the incentives to invest in marketing their output, which in turn shifts consumer expenditure from the young artists' work to the stars'. Thus, longer copyrights have two effects on the expected utility of beginning an artistic career: a positive effect on future earnings in case of succeeding and becoming a star, and a negative effect on current actual returns as a young artist. If success has low probability and is coupled with risk aversion (specifically, if $\rho$ is sufficiently small and relative risk aversion $\sigma>1 / 2$ ) or if future potential earnings as a star are heavily discounted (i.e., if $\theta$ is sufficiently small), then the negative effect of copyright extensions will dominate and reduce the discounted expected utility of an artistic career. ${ }^{21}$ Thus, if stars obtain rents, copyright extensions would reduce artistic creation in the long run by hindering the process of developing and uncovering young talented artists. See Corollary 8 in Appendix A, which generalizes Proposition 2 to the case of strictly positive discount factors.

Results in Proposition 1 are also extended in Appendix A. It is shown that if stars obtain rents and the probability of success as a star is sufficiently low (with $\sigma>1 / 2$ ) or the intertemporal discount factor is sufficiently small, improvements in communication and marketing technologies favoring market concentration by stars (as captured by increases in $\gamma$ ) reduce artistic creation in the long run. Moreover, the optimal copyright term from the point of view of maximizing

\footnotetext{
${ }^{21}$ This is consistent with the empirical analysis of Kretschmer and Hardwick (2007) who, after comparing the different sources of writers' income in Germany and the UK and the skewness of copyright earnings, conclude that current copyright law may exacerbate risk.
} 
artistic creation decreases with the effectiveness $\gamma$ of communication and marketing technologies (see Propositions 9 and 10).

\section{A Continuum of Artist Types}

We now generalize the results in the previous section to a model with a continuum of artist types in terms of their talent. Furthermore, we also show that longer copyrights tend to lower the average talent of senior artists. Thus, in the long run, excessively long copyrights may reduce the total number of artists, their average talent, and social welfare. The key condition for this to occur is that the superstar characteristics of the market are sufficiently strong. In this continuous-talent model, this means that there is a small fraction of artists with very high talent and that talent falls sharply as we consider additional artists from a given pool. In other words, the distribution of talent somewhat approaches the previous case of a two-type distribution of talent.

\subsection{The Setting}

In this section, $\rho$ still denotes the fraction of young artists of each generation that continue as stars in their second life-period. However, $\rho$ is now endogenous. Let $q$ denote an artist's talent and let $q^{M}$ be the talent of the marginal senior artist; i.e., the talent of the least talented active senior artist. We assume that the distribution of talents is the same in every generation of young artists (though the number of young artists may vary) and that the young artists that continue their careers as senior artists are the most talented of their generation. Therefore, the talent of the marginal senior artist is a decreasing function of the fraction of young artists continuing their careers. Denote this function as $q^{M}(\rho)$. We assume the specific functional form

$q^{M}(\rho)=(1+k) e^{-k \rho}$, where $k>0$. The parameter $k$ provides sufficient flexibility to discuss different configurations of the market: $k=0$ would correspond to the case of homogeneous talent, whereas the larger $k$ is, the more skewed the distribution is and the larger the difference of talent between superstars and modest artists. We refer to a larger $k$ as a stronger superstar configuration of the market. Then, the average talent of senior artists in the steady state is $E\left[q^{S}\right]=\frac{1}{\rho}\left(\frac{1+k}{k}-\frac{q^{M}}{k}\right)=\frac{1}{\rho} \frac{1+k}{k}\left(1-e^{-k \rho}\right)$.

To simplify and fit the continuous distribution of talent within the Salop (1979) framework, we assume that artistic talent translates into being quantitatively more creative. That is, a senior artist with talent $q$ creates $q$ artistic goods per period. The number of senior artistic goods created each period is denoted by $N$. Thus, $N=n \cdot E\left[q^{S}\right]$. Moreover, we assume that each artist locates and sells her artistic creations as if each one had been created by a different artist. That is, each artistic creation is symmetrically located around the corresponding circle of characteristics (i.e., either around the stars' circle or around the young artists' circle) regardless 
of the author. ${ }^{22}$ This allows us to maintain the same symmetric monopolistic competition framework with very few changes: the exogeneity of $\rho$ is now substituted with the condition that the marginal senior artist obtains no rents, whereas the relevant number determining prices in the senior sub-market is not the number of senior artists $n$ but the number of senior creations $N$.

We now proceed to analyze the steady state equilibrium. Thus, all of the propositions below refer to the long run. In equilibrium, the fraction of young artists that continue active in the second period as senior artists is such that the marginal senior artist obtains no rents:

$$
q^{M} \cdot \pi^{S}(\omega, N)=F^{S}
$$

where $\pi^{S}(\omega, N)$ is now interpreted as the discounted revenues per senior artistic good. Discounted revenues per senior artistic good are determined by the same expression (11) above except that $N$ substitutes for $n$. Therefore, we have:

$$
q^{M}=\gamma N^{2} \frac{1}{\lambda \gamma \omega-N-\ln (\lambda \beta \gamma \omega / N)} \frac{F^{S}}{Z} \equiv M(N) .
$$

Note that $q^{M} \equiv M(N)$ is a continuous and increasing mapping over the interval $\left[0, N_{2} \equiv \lambda \beta \gamma \omega\right]$. See Figure 1. In turn, the new free entry condition as a young artist is: ${ }^{23}$

$$
F^{Y}=\pi^{Y}(\omega, n)=\frac{1-a(N)}{m^{2}} \lambda Z=\frac{Z \rho^{2}}{\gamma \omega N}\left(E\left(q^{S}\right)\right)^{2} .
$$

Substituting with the expression for $E\left[q^{S}\right]$ yields

$$
q^{M}=1+k\left[1-\left(\gamma \omega N \frac{F^{Y}}{Z}\right)^{1 / 2}\right] \equiv Y(N) .
$$

Note that $q^{M} \equiv Y(N)$ is a continuous and decreasing mapping over the interval $[0, \infty)$. See Figure 1.

The existence of a long-run equilibrium with some degree of artistic diversity requires a positive market share for young artists $(\beta<1)$, some minimum copyright protection, some

\footnotetext{
${ }^{22}$ Note that in a market with a high density of artists, two artistic creations by two different artists may be as similar as two creations by the same artist. Hence, in an artistic market with monopolistic competition, two creations by the same artist may compete with each other in a very similar way as two artistic creations by two different artists.

${ }^{23} \mathrm{We}$ are assuming that each young artist creates one artistic good. Instead, we could assume that talent differences already lead to differences in output when artists are young. Returns during the period as a young artist would then be uncertain. Moreover, $m \cdot E\left[q^{Y}\right]=m[(1+k) / k]\left(1-e^{-k}\right)$ would be the number of youngartist works in the market every period, which would determine their prices and revenues. The main consequence of this setting would be that uncertainty during the period as a young artist is larger, which in turn reduces the expected value of beginning the artistic career. This is equivalent to considering an increase in $F^{Y}$. This setting would make the notation and exposition somewhat heavier without providing any additional insight.
} 
minimum market size with respect to the size of the fixed opportunity costs, and some minimum consumer preference for artistic diversity. Consider the following

Assumption 1: $\lambda \beta / 2>Z / 2 F^{Y}>\gamma \omega>1>\beta$.

If $k$ is sufficiently large, then Assumption 1 is sufficient for the existence of an equilibrium with $N^{*} \geq 2$. To see this, consider Figure 1. Define $q_{1}^{M} \equiv M(2)$ and $q_{2}^{M} \equiv Y(2)$. If $k$ is sufficiently large, Assumption 1 ensures $q_{2}^{M}>q_{1}^{M}>0$. Now, define $N_{1} \equiv Z /\left(F^{Y} \gamma \omega\right)$ and note that $Y\left(N_{1}\right)=1$ and $M\left(N_{1}\right)>1$. Moreover, if $k$ is sufficiently large, Assumption 1 ensures $N_{1}>2$. Therefore, $M\left(N, q^{M}\right)$ and $Y\left(N, q^{M}\right)$ cross at a point $N^{*}$ such that $2<N^{*}<N_{1}$ (also, they guarantee $A>0$ ). This point is the equilibrium number of senior-artist creations, which analytically is determined by expressions (16) and (17):

$$
N^{*}=\frac{1}{\gamma \omega} \frac{Z}{F^{Y}}\left(1-\frac{1}{k} \frac{F^{S}}{\pi^{S}\left(N^{*}, \omega\right)}\right)^{2} .
$$

Note that conditions in Assumption 1 will continue to be met when we consider arbitrarily large values of $\lambda$ as we do below in Proposition 6.

\subsection{Copyrights and Artistic Creation}

How does the equilibrium depend on the length of the copyright term? The following propositions are proven in Appendix B.

Proposition 4 If the artistic market has a sufficiently strong superstar configuration (i.e., if $k$ is sufficiently large), then there exists a finite copyright term $T^{N}$ (i.e., there exists a $\omega^{N}<1$ ) that maximizes artistic creation. Extending the length of the copyright term beyond that point reduces the number of young artists beginning an artistic career and reduces artistic creation in the long run by both young and senior artists. Moreover, the stronger the superstar configuration of the market, the shorter the copyright term that maximizes artistic creation.

Proposition 5 Extending the length of the copyright term increases the fraction of young artists that become senior artists, which involves a reduction in the average talent of senior artists.

When copyrights are extended, young artists that were slightly short of having enough talent to break even as senior artists are then able to cover opportunity costs $F^{S}$. However, the absolute number of young artists as well as senior creation may be reduced in the long run as a result of copyright extensions even if a larger fraction of young artists succeed. The intuition is as follows: if the copyright term is extended, senior artists invest more in marketing. This reduces the size of the young artists sub-market and therefore the number of young artists that are able to begin an artistic career. As a result, the new generation of young artists provides a smaller pool of talent for the next generation of senior artists. The shortage of new highly-talented senior artists is partially compensated by a higher fraction of young artists continuing their careers as senior 
artists. This also means an increase in the share of mediocre senior artists. Overall, senior artistic creation is reduced.

Graphically, an increase in $\omega$ shifts downwards both the $Y\left(N, q^{M}\right)$ and the $M\left(N, q^{M}\right)$ schedules in Figure 1 (recall that Assumption 1 implies $\omega>1 / \lambda \gamma$ ). Given $\omega$, if $k$ is large, then the shift in $Y\left(N, q^{M}\right)$ tends to dominate thereby reducing $N^{*}$. Then, given $k$, if $\omega$ is sufficiently small then the downward shift of $M\left(N, q^{M}\right)$ dominates and implies a new equilibrium with larger $N^{*}$. In between those copyright terms, there is a value $\omega^{N}, 0<\omega^{N}<1$, that maximizes $N^{*}$ (see Appendix B for the proof).

To see the implication for the number of young artists, note that $N=n \cdot E\left[q^{S}\right]=$ $m \cdot \frac{1+k}{k}\left(1-e^{-k \rho}\right)$. Hence, a lower $N$ and a larger $\rho$ imply a lower $m$. Thus, if talent is sufficiently heterogeneous, the number of young artists that begin an artistic career decreases with copyrights, even if a larger fraction of them are able to continue in the market as senior artists. The combination of a smaller entry of young artists and a larger fraction of them continuing as senior artists may result in larger artistic creation if talent were evenly distributed among artists (i.e., if $k$ were low). ${ }^{24}$ However, the larger the parameter $k$ is, the lower the creativity of the marginal senior artist. As a consequence, if $k$ is sufficiently large, the negative effect that greater copyrights have on creation due to fewer potential young artists beginning an artistic career outweighs the positive effect due to a larger fraction of young artists continuing as senior artists. ${ }^{25}$

The mechanism linking copyright regulation to the number of young artists can also be viewed from the perspective of how additional revenues in the artistic industry are allocated across artists. As $k$ tends to 0 , the difference in talent between the most talented artists and the marginal artist goes to zero. Therefore, superstar rents would also tend to zero. If this is the case, the additional revenues accruing to the artistic industry as a result of an extension of copyrights go to help more young artists to continue their career as senior artists. The flatter the distribution of talent, the larger the number of these additional young artists that will continue their $_{\text {careers. }}{ }^{26}$ In contrast, if talent is very unevenly distributed, most additional revenues accruing to the artistic industry that result from a reinforcement of copyrights go to increase the superstars' rents. This does not help artistic creation.

\footnotetext{
${ }^{24}$ The model delivers the standard result (i.e., copyright reinforcements always increase artistic creation) if artistic talent is homogeneous or if the effectiveness of marketing expenditures is very low. That is, if $k$ or $\gamma$ is equal to 0, then we always have $\frac{d N}{d \omega} \frac{\omega}{N}>0$ (see expression (25) in Appendix B). However, as we argue in the Introduction, talent heterogeneity leading to superstar markets as well as vast and effective marketing expenditures are prominent characteristics of artistic markets.

${ }^{25}$ If the second-period expected returns of young artists are taken into account, then increases in superstar rents have a less negative impact on young artists decisions to begin their artistic careers. However, if uncertainty and risk aversion are sufficiently large or if the discount factor is sufficiently low, the same qualitative results hold, as shown in Appendix A for the model with two artist types.

${ }^{26}$ The derivative $\frac{d \rho}{d \omega} \omega$ is decreasing in $k$ as can be seen using expressions (25) and (26) in Appendix B.
} 
Proposition 5 implies that an excessive concentration of revenues in the artistic market can harm artistic creation in the long run, even if the apparent cause of this concentration is an exogenously large heterogeneity of talent. If this is the case, shortening the copyright term can reduce the concentration of sales and revenues, help discover new talent, and raise creation in the long run. Finally, note that the two-types model with small $\rho$ in the previous section can be viewed as a limit case of this continuum of types model with large $k$.

\subsection{Social Welfare}

What are the potential welfare consequences of extending the copyright term in this setting? How does the optimal copyright term depend on the structure of the market? Welfare in this continuum-type model is given by the same expression (14) above. The results in the following proposition are then similar to those found in the framework of the two-types model (see the proof in Appendix B).

Proposition 6 If artistic diversity is sufficiently valuable to consumers (i.e., if $\lambda$ is sufficiently large) and if artistic markets have a sufficiently strong superstar configuration (i.e., if $k$ is sufficiently large), then there is an optimal copyright term $\omega^{W}$ that maximizes long-run social welfare. Extending copyrights beyond that term reduces social welfare due to a negative impact on artistic creation. Moreover, the stronger the superstar configuration of the market, the shorter the optimal copyrights are.

Conceptually, the derivative of welfare with respect to the length of the copyright term in the model with a continuum of types has the same four components than in the two-types model, and the intuition for the results in the proposition is analogous. First, a larger copyright raises the gross utility of consumers as the fraction of people consuming stars' output increases. Again, this positive effect is conditional on the senior artists' output being of higher quality than the young artists' output. Second, utility stemming from artistic variety decreases. Third, marketing costs increase. And fourth, total opportunity costs are reduced as the number of artists decreases. If artistic diversity $\lambda$ is sufficiently valuable, the second and third effects eventually outweigh the first and fourth effects.

Moreover, the more valuable artistic diversity, the closer $\omega^{W}$ is to $\omega^{N}$ (i.e., the closer the copyright term that maximizes welfare is to the one that maximizes artistic creation). This occurs because as $\lambda$ becomes large then only the second effect tends to matter. Thus, if artistic diversity is sufficiently valuable, higher concentration of sales and revenues by a relatively small group of superstars (which is the empirical counterpart of a high $k$ ) calls for shorter copyrights. The details of the argument are the same as those in the previous subsection.

Interestingly, our approach shows that we can have both $\omega^{W}>\omega^{N}$ and $\omega^{W}<\omega^{N}$ (besides having them closer to each other as the preference for diversity increases). This is in contrast with the conventional analysis where we typically have $\omega^{W}<\omega^{N}$ (see, in particular the analysis 
by Landes and Postner, 1989). Moving $\omega$ away from $\omega^{N}$ always reduces $N$. The specific effect of raising $\omega$ above $\omega^{N}$ is that it increases $\rho$, which means reducing the ratio of young artists to senior artists and raising stars' market share. The case $\omega^{W}>\omega^{N}$ is more likely to occur if stars' quality and productivity is large and their opportunity costs are not very high relative to young artists'. If this is not the case, maximizing welfare requires a smaller proportion of (mediocre and/or expensive) senior artists than the proportion associated to maximizing the absolute number of senior artists. Thus, we have $\omega^{W}<\omega^{N}$ (see the formal analysis of this issue in the Appendix D).

If artistic diversity is indeed highly valuable, the last statement in Proposition 6 in combination with the evidence indicating that concentration of sales and revenues in artistic markets has been high and increasing over the last decades would suggest that the length of the copyright term should have been shortened. Nonetheless, the length of the copyright term has been increased periodically over time. Does this involve a contradiction between the analysis in this paper and the facts? The answer is negative. To explain the trend toward longer copyrights, it is more appropriate to refer to the political economy of copyright regulation than to refer to the normative economics of optimal copyrights. In that respect, note that the value of an extension of the copyright term for a copyright holder increases as communication and marketing technologies improve and as the market for artistic goods expands and becomes more global (note that the stars' revenues increase with $\gamma$ and $Z$ ). Moreover, copyright extensions for artistic goods that were created in the past are even more lucrative for copyright holders because the main costs of creating and promoting the good have already been paid. Hence, over time, we can expect increased lobbying by copyright holders in favor of copyright extensions even if this reduces social welfare.

\section{Concluding Comments}

Artistic talent is rare and difficult to recognize. It is developed and sorted out through artistic careers that most often end in failure. Understanding the long-run consequences of copyright regulation for artistic creation requires understanding how this regulation affects young artists' opportunities and incentives to begin an artistic career. This paper takes a professional career approach to the analysis of optimal copyright regulation and accounts for several important facts of artistic markets that have been neglected in the previous literature. Such an approach provides new insights. Long copyrights increase superstar market concentration and can reduce the absolute number of young artists being able to pursue artistic careers while increasing the proportion of mediocrities within the group of senior artists. As a result, in the long run, excessively long copyrights can reduce artistic creation, the average talent of artists, and social welfare.

Copyrights should adapt to changes in the technological and economic environment. For more than a century, technological and economic changes have favored superstar market concentration. 
The results in this paper suggest that copyrights should have been shortened in that scenario. Instead, most countries kept extending copyrights, which can be explained in terms of the greater incentives for lobbying in favor of copyright extensions that larger superstar rents create. More recent technological, political, and cultural changes are having mixed consequences on superstars' market share. New copying and communication technologies, such as the Internet, seem to be working against concentration, whereas changes in the economic and political environment have facilitated the globalization of culture, which tends to favor superstars. Information about how concentration in artistic markets is changing is an important key to determining the direction in which copyright regulation should be adjusted.

The stronger the superstar configuration of artistic markets, the larger the share of additional revenues created by extensions of the copyright term that will accrue to superstars. This increases the likelihood that copyright extensions reduce young artists' economic opportunities to begin an artistic career. Copyright regulation cannot affect the uneven distribution of talent. However, it can affect how the distribution of talent translates into a distribution of revenues. Increasing the allocation of financial resources towards superstar rents, which are highly discounted by time and risk as components of the expected value of an artistic career, may be wasteful and even counterproductive as a way to promote artistic creation. The optimal length of the copyright term decreases with the degree of superstar market concentration. Policies aimed at increasing young artists' opportunities to have an audience and to test and develop their skills may be more effective in promoting talent and artistic creation than increasing superstar revenues.

\section{References}

[1] Adler, M., (1985): Stardom and Talent. American Economic Review 75, 208-212.

[2] AEVAL - National Agency for the Evaluation of Public Policies and Quality of Services (2008): Evaluation of the system of collective management of copyright and related rights, Spanish Ministry of the Presidency, Madrid. Available at http://www.aeval.es/comun/pdf/evaluaciones/E12eng.pdf.

[3] Akerloff, G., K. Arrow, T. Bresnahan, J. Buchanan, R. Coase, L. Cohen, M. Friedman, J. Green, R. Hahn, T. Hazlett, C. Hemphill, R. Litan, R. Noll, R. Schmalensee, S. Shavell, H. Varian, and R. Zeckhauser (2002): Amici Curiae in Support of Petitioners in the Supreme Court of the United States, Eldred versus Ashcroft. Available as Technical Report 01618, Harvard Law School.

[4] Alcalá, Francisco, and Miguel González-Maestre (2010): "Copying, Superstars, and Artistic Creation". Forthcoming in Information Economics and Policy. 
[5] Bar-Isaac, Heski, Guillermo Caruana and Vicente Cuñat (2010): "Search, Design, and Market Structure," mimeo.

[6] Boldrin, Michele, and David K. Levine (2006): "Growth and Intellectual Property," NBER working paper 12769, Cambridge, Mass.

[7] Chisholm, Darlene C. (2004): "Two-Part Share Contracts, Risk and Life Cycle of Stars: Some Empirical Results from Motion Picture Contracts," Journal of Cultural Economics, $28,37-56$.

[8] Crain, W. Mark, and Robert D. Tollison (2002). "Consumer Choice and the Popular Music Industry: A Test of the Superstar Theory," Empirica, 29(1), 1-9.

[9] Gayer, Amit, and Oz Shy (2006): "Publishers, Artists, and Copyright Enforcement," Information Economics and Policy, 18(4), 374-384.

[10] Grossman, Gene M., and Edwin L. Lai (2004): "International Protection of Intellectual Property," American Economic Review, 94(5), 1635-1653. Corrigendum in vol. 96(1), 456, 2006.

[11] Hamlen, William A. Jr., (1991): "Superstardom in Popular Music: Empirical Evidence", Review of Economics and Statistics, 73(4), 729-33.

[12] Hirshleifer, Jack, and John G, Riley (1979): "The Analytics of Uncertainty and InformationAn Expository Survey," Journal of Economic Literature, 17(4), 1375-1421.

[13] IFPI (2010): "Investing in music". Report available at http://www.ifpi.org/content/library/investing_in_music.pdf

[14] Johnson, William R. (1978): "A Theory of Job Shopping," Quarterly Journal of Economics, 92(2), 261-278.

[15] Kretschmer, Martin. et al. (2008): "Creativity Stifled? A joint academic statement on the proposed copyright term extension for sound recordings" European Intellectual Property Review, 30(9), 341-347. Available at http://www.cippm.org.uk/downloads/EIPR\%20Bournemouth\%20Statement.pdf

[16] Kretschmer, Martin, and Philip Hardwick (2007): "Authors' Earnings from Copyright and Non-Copyright Sources: A survey of 25,000 British and German writers," London/Bournemouth: ALCS/CIPPM. Available at http://www.cippm.org.uk/downloads/ACLS\%20Full\%20report.pdf

[17] Kretschmer, Martin. et al. (2009): Joint Press Release by European Academics (11 March 2009) on the Proposed Directive for a Copyright Term Extension. Available in http://www.cippm.org.uk/downloads/Press\%20Release\%20Copyright\%20Extension.pdf 
[18] Krueger, Alan B. (2005): The Economics of Real Superstars: The Market for Rock Concerts in the Material World," Journal of Labor Economics, 23(1), 1-30.

[19] Landes, William M., and Richard A. Posner (1989): "An Economic Analysis of Copyright Law," Journal of Legal Studies, 18(2), 325-363.

[20] Liebowitz, Stan, and Stephen Margiolis (2003): "17 Famous Economists Weigh in on Copyright: The Role of Theory, Empirics, and Network Effects." Technical report, Social Science Research Network.

[21] Liebowitz, Stan J. (2007): "What are the consequences of the European Union extending copyright length for sound recordings?" Prepared for the International Federation of the Phonographic Industry (IFPI). Available at http://www.ifpi.com/content/library/liebowitz-study-aug2007.pdf

[22] MacDonald, Glenn M. (1988): "The Economics of Rising Stars," American Economic Review, 78(1), 155-167.

[23] Novos, Ian E., and Michael Waldman (1984): "The Effects of Increased Copyright Protection: An Analytical Approach", Journal of Political Economy, 92(2), 236-46.

[24] Peitz, Martin, and Patrick Waelbroeck (2005). "An Economist's Guide to Digital Music". CESifo Economic Studies, 51, 359-428.

[25] Rosen, Sherwin (1981): "The Economics of Superstars", American Economic Review, 71(5), 845-858.

[26] Rothenbuhler, Eric, and John Dimmick (1982): "Popular Music: Concentration and Diversity in the Industry, 1974-1980." Journal of Communication, 32(1), 143-149.

[27] Salop, Steven C. (1979): "Monopolistic Competition with Outside Goods". Bell Journal of Economics, 10(1), 141-156.

[28] Scherer, F.M., (2006): "The Evolution of Music Markets," in Victor A. Ginsburgh and David Throsby, Handbook on the Economics of Art and Culture, Volume 1, chapter 4, 123-143.

[29] Soloveichik, Rachel (2010a): "Music as a Capital Asset," Unpublished.

[30] Soloveichik, Rachel (2010b): "Artistic Originals as a Capital Asset," American Economic Review, 110-114.

[31] Spierdijk, Laura, and Mark Voorneveld (2009): "Superstars without Talent? The Yule Distribution Controversy," The Review of Economics and Statistics, 91(3), 648-652. 
[32] Sutton, John (1991): Sunk Costs and Market Structure: Price Competition, Advertising, and the Evolution of Concentration. MIT Press, Cambridge, MA.

[33] Terviö, Marko (2009): "Superstars and Mediocrities: Market Failure in The Discovery of Talent," Review of Economic Studies, 76(2), 829-850.

[34] Young, S. Mark, James J. Gong, Wim A. Van der Stede, Tatiana Sandino, and Fei Du (2008): "The Business of Selling Movies," Strategic Finance, March.

[35] Varian, Hal R. (2005): "Copying and copyright," Journal of Economic Perspectives, 19(2), 121-138.

\section{Appendix A: The model with positive discount factor}

In this Appendix, we generalize the analysis to the case of a young artists' discount factor $\theta$ that is strictly positive. Furthermore, we also consider the possibility that stars' constraint $\pi_{t}^{S} \geq F^{S}$ is binding. The analysis of senior artists' optimal decisions carried out in Section 3 remains unchanged. To save notation, in this appendix we assume $\lambda=1$. We proceed directly to consider the symmetric steady state equilibrium of the model.

\subsection{A graphical exposition}

If stars' opportunity cost is binding, it may happen that some young artists that reveal their talent in their first life-period do not become stars in their second life-period. They will be indifferent to do so, whereas any increase in the number of stars would place their earnings below opportunity costs. On the contrary, if stars' earnings are strictly above their opportunity costs, all young artists that show talent will want to stay in the artistic market in their second life-period as senior artists. These arguments are summarized in the following constraint that replaces (2):

$$
\begin{aligned}
n_{t} & \leq \rho m_{t-1} \\
\left(\pi_{t}^{S}-F^{S}\right)\left(n_{t}-\rho m_{t-1}\right) & =0 .
\end{aligned}
$$

Depending on whether the constraint $n_{t} \leq \rho m_{t-1}$ is binding, we use $n_{t+1} / m_{t}=\rho$ or $\pi_{t}^{S}=F^{S}$ to substitute in expression (1) to determine the equilibrium.

Intuitively, the number of superstars is limited by either the revenue that these artists obtain (which must be at least as large as their opportunity costs), or by the inflow of new talented young artists (which in turn depends on the life-long expected utility of beginning an artistic career). The long-run consequences for artistic creation of changes in copyright regulation and marketing technologies depend on which of these two constraints is limiting the number of active senior artists. 
The $S(\omega, n)$ locus Consider the pairs of $\omega$ and $n$ that satisfy constraint $\pi_{t}^{S} \geq F^{S}$ with equality; i.e., the combinations of copyrights and number of stars leading to a stars' income level equal to their opportunity costs. We denote this locus by $S(\omega, n)$ :

$$
S(\omega, n)=:\left\{(\omega, n): \pi^{S}(\omega, n)=F^{S}\right\}
$$

where $\pi^{S}(\omega, n)$ is given by (11). Differentiating $S(\omega, n)$ with respect to $n$ and $\omega$ yields $d n / d \omega=$ $\frac{\gamma-1 / \omega}{2 F^{S} \gamma n / Z+1-1 / n}>0$ (note that $a(n)=1-n / \gamma \omega>0$ ). Therefore, $S(\omega, n)$ has a positive slope, as shown in Figure 2. Intuitively, a longer copyright term increases stars' revenues, thereby allowing stars to cover their opportunity costs even if the number of stars is larger (i.e., even if there is more competition and prices of artistic goods are lower). It is useful to define $s: R \rightarrow R$ as the function that for each $\omega$ yields the value of $n$ that satisfies (20). Note that a pair $(\omega, n)$ satisfies constraint $\pi_{t}^{S} \geq F^{S}$ if and only if $n \leq s(\omega)$.

The $Y(\omega, n)$ locus Substituting (12) into young artists' free-entry condition (1) yields:

$$
\left[\frac{(1-a)}{m^{2}} Z\right]^{1-\sigma}+\theta \frac{n}{m}\left(\left[\pi^{S}(\omega, n)\right]^{1-\sigma}-\left[F^{Y}\right]^{1-\sigma}\right)=\left[F^{Y}\right]^{1-\sigma} .
$$

Now, consider the combinations of $\omega$ and $n$ satisfying this expression and constraint (19) with equality; i.e., the combinations of $\omega$ and $n$ providing an expected discounted revenue of beginning an artistic career equal to opportunity costs when all talented young artists will be willing to continue their career as stars. We denote this locus by $Y(\omega, n)$. After using $(10), Y(\omega, n)$ is given by the following expression:

$$
Y(\omega, n)=:\left\{(\omega, n):(1+\theta \rho)\left[\frac{\rho^{2}}{F^{Y}}\right]^{\sigma-1}=\left(\frac{\gamma n \omega}{Z}\right)^{\sigma-1}+\theta \rho^{2 \sigma-1}\left[\pi^{S}(\omega, n)\right]^{1-\sigma}\right\} .
$$

Differentiation with respect to $\omega$ and $n$ yields:

$$
\frac{d n}{d \omega} \frac{\omega}{n}=-\frac{g-\theta \rho^{2 \sigma-1}\left(n \cdot \pi^{S}\right)^{1-\sigma} \frac{\partial \pi^{S}}{\partial \omega} \frac{\omega}{\pi^{S}}}{g-\theta \rho^{2 \sigma-1}\left(n \cdot \pi^{S}\right)^{1-\sigma} \frac{\partial \pi^{S}}{\partial n} \frac{n}{\pi^{S}}}
$$

where $g=(\gamma \omega / Z)^{\sigma-1}$. Note that the product $n \cdot \pi^{S}$ as well as $\frac{\partial \pi^{S}}{\partial \omega}$, and $\frac{\partial \pi^{S}}{\partial n}$ are bounded from above by $Z$. Hence, if there is a sufficiently small probability $\rho$ of becoming a star (assuming $\sigma>1 / 2$ ) or if the time needed to emerge as a talented artist is sufficiently long (which implies a small discount factor $\theta$ ), then $d n / d \omega$ is negative. Both circumstances seem to characterize artistic markets as argued in the Introduction. Under this assumption, the $Y(\omega, n)$ locus has a negative slope as shown in Figure 2. The reason is that longer copyrights increase stars' revenues, marketing, and market share. As a consequence, they reduce the number of young artists that can cover their opportunity costs. Moreover, if (19) is binding, then $n$ is determined by the number of young artists that start the career and have talent (i.e., a fraction $\rho$ ). Therefore, $n$ is decreasing in $\omega$. It is useful to define $y: R \rightarrow R$ using $Y(\omega, n)$, as the function that for each 
$\omega$ yields the value of $n$ that satisfies $(22)$. A pair $(\omega, n)$ satisfies constraint (19) if and only if $n \leq y(\omega)$.

Now, define $\underline{\omega}$ as the copyright satisfying $\pi^{S}(\underline{\omega}, 2)=F^{S}$ and $n_{1}$ as the number of senior artists satisfying $Y\left(\underline{\omega}, n_{1}\right)$. Note that if $\gamma$ is sufficiently large, then $0<\underline{\omega}<1$ (also $n<\beta \gamma \omega$, which guarantees $A>0$ ), and that if $Z$ is sufficiently large then $n_{1}>2$. See Figure 2. Additionally, define $n_{2}$ as the $n$ satisfying $Y\left(1, n_{2}\right)$, and define $n_{3}$ as the $n$ satisfying $S\left(1, n_{3}\right)$. Note that we always have $n_{3}>2$ and that if $\rho$ is sufficiently low, we also have $n_{2}<2$. Hence if $\rho$ is sufficiently low, we have $n_{3}>n_{2}$. These circumstances together guarantee that $Y(\omega, n)$ and $S(\omega, n)$ cross each other for some $\omega^{n} \in(\underline{\omega}, 1)$. Hence we have the following:

Proposition 7 If the probability of success as a star $\rho$ is sufficiently small and relative risk aversion $\sigma$ is larger than $1 / 2$, and if marketing efficiency $\gamma$ and market size $Z$ are sufficiently large, then the long-run equilibrium number of senior artists $n^{*}$ satisfies $n^{*} \geq 2$. Moreover, $n^{*}$ as a function of the length of the copyright term is given by $n^{*}=\min [y(\omega), s(\omega)]$, and there exists $\omega^{n} \in(\underline{\omega}, 1)$ that maximizes $n^{*}$.

Proof. Pairs $(\omega, n)$ on or below the locus $S(\omega, n)$ in Figure 2 satisfy the constraint $\pi_{t}^{S} \geq F^{S}$, whereas pairs on or below $Y(\omega, n)$ satisfy (1) and the constraint (19). Thus, using $s(\omega)$ and $y(\omega)$ we can determine the long-run equilibrium number of senior artists $n^{*}$ as $n^{*}=\min [y(\omega), s(\omega)]$. Then, recall that if the probability of success as a star $\rho$ is sufficiently small and if $\sigma>1 / 2$, then we have $d n / d \omega<0$ in schedule $Y(\omega, n)$ and $n_{3}>n_{2}$. Moreover, recall that if $\gamma$ is sufficiently large, then $\underline{\omega}<1$, whereas if market size $Z$ is sufficiently large, then $n_{1}>2$. This implies that for some $\omega^{n} \in(\underline{\omega}, 1), Y(\omega, n)$ and $S(\omega, n)$ cross each other. Finally, the positive slope of $S(\omega, n)$ and the negative slope of $Y(\omega, n)$ within the interval $[\underline{\omega}, 1]$ imply that the long number of senior artists is maximized for this copyright term $\omega^{n}$.

The assumption with the most important conceptual content in this proposition is that $\rho$ has to be sufficiently small. Our results crucially depend on this assumption implying that revenues in artistic markets are very uncertain and unevenly distributed. This is analogous to the assumption in the continuous-type model requiring that markets have a superstar configuration that is sufficiently strong. If earnings were homogeneous across artists, longer copyrights would always stimulate artistic creation. The other assumptions have a more technical nature. Marketing expenditures must be sufficiently effective for them to be non-negative. This requires $\gamma$ to be sufficiently large. In turn, due to artists' fixed opportunity cost, market size $Z$ has to be sufficiently large for the number of artists to be at least 2 .

Solid lines in Figure 2 indicate the segments of $y(\omega)$ and $s(\omega)$ that determine $n^{*}$. Note that if senior artists obtain revenues above their opportunity costs, then $y(\omega)$ is the relevant schedule determining $n^{*}$. The following corollary is then immediate:

Corollary 8 If stars obtain rents, then extending the copyright length reduces artistic creation in the long run. 


\subsection{Technical innovations and market expansions}

Now we consider how structural changes in the relevant environment affect artistic creation in the long run under the equilibrium conditions stated in Proposition 7. The effect depends on whether the relevant constraint for artistic careers is the $S(\omega, n)$ locus or the $Y(\omega, n)$ one. An increase in market size $Z$ shifts both schedules upwards, such that $n$ increases regardless of $\omega$. In turn, an increase in $\gamma$ shifts the $Y(\omega, n)$ schedule downwards and the $S(\omega, n)$ schedule upwards (see Figure 3, where $\gamma_{2}>\gamma_{1}$ ). Therefore, the impact of $\gamma$ on $n$ depends on $\omega$. If $\omega$ is to the right of $\omega_{1}^{n}$ (i.e., if stars obtain rents), then an increase of $\gamma$ leads to a reduction of $n$. These results are summarized in the following proposition.

Proposition 9 Increases in market size always increase artistic creation in the long run, regardless of the copyright term. If stars obtain rents, improvements in communication and marketing technologies favoring market concentration by stars (i.e., increases in $\gamma$ ) reduce artistic creation in the long run.

Proof. We have to demonstrate that when $\gamma$ increases the $S(\omega, n)$ schedule shifts upwards whereas the $Y(\omega, n)$ schedule shifts downwards; and that when $Z$ increases, both schedules shift upwards. The directions of the shifts can be obtained by differentiating $n$ with respect to $\gamma$ and $Z$ in $Y(\omega, n)$ and $S(\omega, n)$ while taking $\omega$ as a constant. To analyze the effects of $\gamma$ and $Z$ on $S(\omega, n)$ note first that:

$$
\begin{aligned}
\frac{\partial \pi^{S}}{\partial Z} & =\pi^{S} / Z>0 \\
\frac{\partial \pi^{S}}{\partial \gamma} & =Z \frac{1}{\gamma n^{2}}\left[1-\frac{1}{n}+\frac{1}{n} \ln \left(\frac{\beta \gamma \omega}{n}\right)\right]>0 \\
\frac{\partial \pi^{S}}{\partial n} & =-\frac{Z}{n}\left[\frac{2 \pi^{S}}{Z}+\frac{1}{\gamma n}\left(1-\frac{1}{n}\right)\right]<0 .
\end{aligned}
$$

Let $n^{S}$ be the level of $n$ implied by $S(\omega, n)$. Differentiating $S(\omega, n)$ with respect to $n$ and $Z$ and with respect to $n$ and $\gamma$ yields, respectively:

$$
\frac{d n^{S}}{d Z}=-\left(\frac{\partial \pi^{S}}{\partial Z} / \frac{\partial \pi^{S}}{\partial n}\right)>0 ; \quad \frac{d n^{S}}{d \gamma}=-\left(\frac{\partial \pi^{S}}{\partial \gamma} / \frac{\partial \pi^{S}}{\partial n}\right)>0
$$

Therefore, the schedule $S(\omega, n)$ shifts upwards when $Z$ or $\gamma$ increase. Now, let $n^{Y}$ be the level of $n$ implied by $Y(\omega, n)$. Differentiating $Y(\omega, n)$ yields:

$$
\begin{aligned}
\frac{d n^{Y}}{d Z} \frac{Z}{n^{Y}} & =\frac{g-\theta \rho^{2 \sigma-1}\left(n \cdot \pi^{S}\right)^{1-\sigma} \frac{\partial \pi^{S}}{\partial Z} \frac{Z}{\pi^{S}}}{g-\theta \rho^{2 \sigma-1}\left(n \cdot \pi^{S}\right)^{1-\sigma} \frac{\partial \pi^{S}}{\partial n} \frac{n}{\pi^{S}}}>0 \\
\frac{d n^{Y}}{d \gamma} \frac{\gamma}{n^{Y}} & =-\frac{g-\theta \rho^{2 \sigma-1}\left(n \cdot \pi^{S}\right)^{1-\sigma} \frac{\partial \pi^{S}}{\partial \gamma} \frac{\gamma}{\pi^{S}}}{g-\theta \rho^{2 \sigma-1}\left(n \cdot \pi^{S}\right)^{1-\sigma} \frac{\partial \pi^{S}}{\partial n} \frac{n}{\pi^{S}}}<0 .
\end{aligned}
$$


Note that we always have $n \geq 2$, that the product $n \cdot \pi^{S}$ as well as $\frac{\partial \pi^{S}}{\partial Z}, \frac{\partial \pi^{S}}{\partial n}$, and $\frac{\partial \pi^{S}}{\partial \gamma}$ are bounded from above by $Z$ and that $\pi^{S}$ is bounded from below by $F^{S}$. Hence, assuming $\sigma>1 / 2$, if $\rho$ or $\theta$ is sufficiently small, then $d n^{Y} / d Z$ is positive whereas $d n^{Y} / d \gamma$ is negative. Therefore, if $Z$ (respectively, $\gamma$ ) increases, then the schedule $Y(\omega, n)$ shifts upwards (resp., downwards). Finally, note that an increase in $Z$ raises $n$ regardless of $\omega$ whereas the impact of $\gamma$ depends on $\omega$. If $\omega$ is to the right of $\omega_{1}^{n}$ (i.e., if stars obtain rents), then an increase of $\gamma$ leads to a reduction of $n$. See Figure 3.

How should the copyright term adjust as the economic environment changes? It is clear from Figure 2 that if the $S(\omega, n)$ and $Y(\omega, n)$ schedules cross for some copyright term $\omega^{n}>0$, this is the term maximizing long-run artistic creation. We can thus use this graphical analysis to explore how the maximizing copyright term changes as a result of changes in the economy. It is easy to check using Figure 3 that an increase in $\gamma$ always leads to a shorter optimal term $\omega^{n}$.

Proposition 10 Improvements in communication and marketing technologies as well as reductions in the barriers to the globalization of culture (as captured by increases in $\gamma$ ) shortens the length of the copyright term that maximizes long-run artistic creation.

\section{Appendix B: Relegated proofs}

\section{Proof of Proposition 3}

Consider the derivative of (14) with respect to $\omega$. Recalling that $\frac{d n}{d \omega} \frac{\omega}{n}=-1$ and that $\frac{d a}{d \omega}=2 \frac{1-a}{\omega}>0$ yields:

$$
\begin{aligned}
\frac{d W}{d \omega} \frac{1}{Z}= & \left(Q^{S}-Q^{Y}\right) \frac{d a}{d \omega}+\frac{\lambda}{4 n}\left[\left((1-a) \frac{\rho}{\omega}+\frac{a}{\omega}\right) \frac{d n}{d \omega} \frac{\omega}{n}-(1-\rho) \frac{d a}{d \omega}\right]-\frac{d A}{d \omega} \frac{1}{Z} \\
& -\left(\frac{F^{S}}{Z}+\frac{F^{Y}}{Z \rho}\right) \frac{d n}{d \omega} \\
= & \left(Q^{S}-Q^{Y}\right) \frac{\rho^{2}}{\gamma^{2}} \frac{2 Z}{\omega^{3} \lambda F^{Y}}-\frac{1}{4}\left(\lambda \frac{\gamma}{\rho^{2}} \frac{F^{Y}}{Z}+\frac{1-\rho}{\gamma \omega^{2}}\right)-\frac{d A}{d \omega} \frac{1}{Z}+\frac{\rho}{\gamma} \frac{1}{\omega^{2}}\left(\rho \frac{F^{S}}{F^{Y}}+1\right)
\end{aligned}
$$

where $\frac{d A}{d \omega}=\left[2+\ln \left(\frac{\beta \gamma^{2} \lambda \omega^{2} F^{Y}}{Z \rho^{2}}\right)\right] \frac{F^{Y}}{\rho^{2}}>0$. This derivative is negative if $\lambda$ is sufficiently large or $\rho$ is sufficiently small.

\section{Proof of Proposition 4}

Differentiating expression (18) yields:

$$
\epsilon_{N \omega} \equiv \frac{d N}{d \omega} \frac{\omega}{N}=-\frac{k \cdot \pi^{S} / F^{S}-1-2 \frac{\partial \pi^{S}}{\partial \omega} \frac{\omega}{\pi^{S}}}{k \cdot \pi^{S} / F^{S}-1-2 \frac{\partial \pi^{S}}{\partial N} \frac{N}{\pi^{S}}} .
$$

If $k$ is sufficiently large, then this derivative is positive for short copyrights and negative for long copyrights, which implies the potential negative effect of the extension of copyrights on artistic creation stated in Proposition 4. Note that if Assumption 1 holds, in equilibrium we 
have $\pi^{S}>0$ as well as $\frac{\partial \pi^{S}}{\partial N} \frac{N}{\pi^{S}}<0$ and $\frac{\partial \pi^{S}}{\partial \omega} \frac{\omega}{\pi^{S}}>0$. Substitute with $N=0$ in (15) and (17), and define $\underline{\omega}$ as the copyright solving $k \cdot \pi^{S}(\underline{\omega}, 0)=F^{S}$. This is a lower bound for the copyright term: below this level, no senior artist would be able to pay for her opportunity $\operatorname{costs} F^{S}$. As $\omega$ approaches $\underline{\omega}$ from above, (15)-(17) yield that $N$ tends to $0, k \cdot \pi^{S} / F^{S}$ tends to 1 , and therefore the derivative in $(25)$ is positive.

In turn, for any $\omega, \underline{\omega}<\omega \leq 1$, if $k$ is sufficiently large then expression (25) is negative. To see this note that $N^{*}$ is bounded from above by $Z / \gamma \omega F^{Y}$ and from below by 2 (see Figure 1). Hence, (11) and Assumption 1 imply that $\pi^{S}$ is bounded from below above zero and that $\partial \pi^{S} / \partial \omega$ is bounded from above. Therefore, if $k$ is sufficiently large, there is a copyright term $\omega^{N}, \underline{\omega}<\omega^{N}<1$, such that $\frac{d N}{d \omega} \frac{\omega}{N}=0$ and $N^{*}$ is maximized.

Now, to show that $\frac{d \omega^{N}}{d k}<0$, note first that in a neighborhood of the maximizer $\omega^{N}$ we have $d^{2} N / d \omega^{2}<0$. Then we have to show that $\frac{d^{2} N}{d \omega d k}<0$ (or, equivalently, that $\frac{d \epsilon_{N \omega}}{d k}<0$ ) in that neighborhood. Using (25) note that the sign of $\epsilon_{N \omega}$ in a small neighborhood of $\omega^{N}$ is given by the sign of $H=-k \frac{\pi^{S}}{F^{S}}+1+2 \frac{\partial \pi^{S}}{\partial \omega} \frac{\omega}{\pi^{S}}$. The derivative with respect to $k$ yields $\frac{d H}{d k}=-\frac{\pi^{S}}{F^{S}}-\left[\frac{\partial \pi^{S}}{\partial N} \frac{N}{\pi^{S}}-2 \frac{d\left(\frac{\partial \pi^{S}}{\partial \omega} \frac{\omega}{\pi^{S}}\right)}{d N} \frac{N}{k}\right] \frac{d N}{d k} \frac{k}{N}$. In turn, implicit differentiation of (18) yields $\frac{d N}{d k} \frac{k}{N}=2 /\left(k \frac{\pi^{s}}{F^{S}}-1-2 \frac{\partial \pi^{s}}{\partial N} \frac{N}{\pi^{s}}\right)$. Recall that $\pi^{S}$ is bounded from below above zero whereas $\frac{\partial \pi^{S}}{\partial N} \frac{N}{\pi^{S}}$ is bounded from above. Hence $\lim _{k \rightarrow \infty} \frac{d N}{d k} \frac{k}{N}=0$. Moreover, if $k$ is sufficiently large we have $\frac{d H}{d k}<0$. Therefore, $\frac{d \epsilon_{N \omega}}{d k}<0$ in a neighborhood of $\omega^{N}$.

\section{Proof of Proposition 5}

Note from $(25)$ that we always have $\epsilon_{N \omega}>-1$. Then taking into account that $q^{M}=$ $(1+k) e^{-k \rho}$ and differentiating (17) with respect to $\omega$ yields the result in Proposition 5:

$$
\frac{d \rho}{d \omega} \omega=\frac{1}{2} \frac{e^{k \rho}-1}{k}\left(1+\epsilon_{N \omega}\right)>0 .
$$

\section{Proof of Proposition 6}

Welfare is:

$$
\begin{aligned}
W= & {\left[Q^{S} a Z+(1-a) Q^{Y} Z\right]-\left[a Z \frac{\lambda}{4 N}+(1-a) Z \frac{\lambda}{4 m}\right]-A-c Z-n F^{S}-m F^{Y} } \\
= & Z\left[Q^{S}-\frac{Q^{S}-Q^{Y}}{\gamma \lambda} \frac{N}{\omega}+\left(\frac{1}{\gamma}-\lambda\left(\frac{N}{\omega}\right)^{-1}\right) \frac{1}{4 \omega}-\left(\frac{1}{16} \frac{F^{Y}}{\gamma Z}\right)^{1 / 2}\left(\frac{N}{\omega}\right)^{1 / 2}\right]-A-c Z \\
& -\rho\left(\frac{N}{\omega}\right)^{1 / 2}\left(\frac{F^{Y}}{Z} \gamma\right)^{-1 / 2}\left(F^{S}+F^{Y} / \rho\right) .
\end{aligned}
$$


Taking derivatives yields:

$$
\begin{aligned}
\frac{d W}{d \omega} \frac{\omega}{Z} \frac{1}{\lambda}= & \frac{Q^{S}-Q^{Y}}{\gamma \lambda^{2}} \frac{N}{\omega}\left(1-\epsilon_{N \omega}\right)+\frac{1}{4}\left[\frac{1}{N} \epsilon_{N \omega}-\frac{1}{\lambda \gamma \omega}\right]-\frac{1}{\lambda} \frac{d A}{d \omega} \frac{\omega}{Z} \\
& +\frac{1}{2 \lambda}\left(N \frac{F^{Y}}{\gamma \omega Z}\right)^{1 / 2}\left[\left(\frac{5}{4}+\rho \frac{F^{S}}{F^{Y}}\right)\left(1-\epsilon_{N \omega}\right)-\frac{1}{k} \frac{1+\epsilon_{N \omega}}{\left(\frac{Z}{\gamma \omega N F^{Y}}\right)^{1 / 2}-1} \frac{F^{S}}{F^{Y}}\right] ;
\end{aligned}
$$

where $\epsilon_{N \omega} \equiv \frac{d N}{d \omega} \frac{\omega}{N}$ (which is negative if $k$ is sufficiently large: Proposition 5) and $\frac{1}{\lambda} \frac{d A}{d \omega} \frac{\omega}{Z}=$ $\frac{1}{\lambda \gamma N}\left(1-\left[1+\ln (\beta \gamma \lambda \omega / N] \epsilon_{N \omega} \frac{1}{Z}\right)\right.$. Note first that if $\omega$ is sufficiently close to zero the above expression would be positive (as long as Assumption 1 still holds). However, given a copyright term $0<\omega<1$, for $\lambda$ and $k$ sufficiently large, this derivative becomes negative. To see this, recall that $\epsilon_{N \omega}>-1, N$ is bounded $\left(N<Z / F^{Y} \gamma \omega<\lambda \beta \gamma \omega\right)$ as well as $\rho(\rho \leq 1)$, and that $\lim _{k \rightarrow \infty} \epsilon_{N \omega}=-1$ (see (25)) and $\frac{d A}{d \omega} \frac{\omega}{Z}>0$. Hence there is a copyright term $\omega^{W}, 0<\omega^{W}<1$, that maximizes social welfare.

Now, how does the optimal copyright change as the superstar configuration of the market raises? As the value of artistic diversity $\lambda$ increases, the copyright that maximizes social welfare $\omega^{W}$ becomes arbitrarily close to the one that maximizes senior artistic creation $\omega^{N}$. Formally, using expression (28) we have $\lim _{\lambda \rightarrow \infty} \frac{d W}{d \omega} \frac{\omega}{Z} \frac{1}{\lambda}=\frac{1}{4} \frac{1}{N} \epsilon_{N \omega}$. Hence, for $\lambda$ large, $\frac{d W}{d \omega} \rightarrow 0$ at $\omega^{N}$ (which is the copyright such that $\epsilon_{N \omega}=0$ ). Thus, for $\lambda$ large, the cross-derivative of (28) with respect to $k$ evaluated at $\omega^{N}$ yields:

$$
\frac{d W}{d \omega d k} \frac{\omega}{Z} \frac{1}{\lambda}=\frac{1}{4 N}\left[\frac{d \epsilon_{N \omega}}{d k}-\epsilon_{N \omega} \frac{d N}{d k} \frac{1}{N}\right]=\frac{1}{4 N} \frac{d \epsilon_{N \omega}}{d k}<0 .
$$

Therefore, we conclude that the optimal copyright term is shorter in markets where $k$ is larger.

\section{Appendix C: Generalizations of the advertising function}

In this Appendix we generalize the role of advertising in the model in several directions. First we consider the case in which young artists can also advertise. Second, we generalize the functional form of the advertising function and also assume that each star's expenditure in advertising has an individual effect on the perceived quality of her specific work in addition to the positive effect on stars' aggregate market share.

\subsection{The case with stars' and young artists' advertising}

In the main text we assume that young artists do not advertise. In this appendix we introduce young artists' advertising symmetrically to stars' advertising. Consistently with the assumption in the main text, we show that if the ratio of young artists to stars is high enough, young artists do not advertise in equilibrium whereas stars do. 
Let $a^{S}$ and $a^{Y}$ be, respectively, stars' and young artists' market shares. Consistently with the interpretation of advertising in the main text, $a^{S}$ is also the fraction of consumers that are informed about stars' quality (which is increasing in stars' advertising $A^{S}$ ), and $a^{Y}$ is the fraction of consumers that are informed about young artists' quality but are not informed about stars' quality (which is increasing in young artists' advertising $A^{Y}$, and decreasing in stars' advertising). We assume the following expressions, which are symmetric to the one in the main text:

$$
\begin{aligned}
a^{S} & =1-\beta \cdot e^{-\gamma n A^{S} / Z}, \\
a^{Y} & =\beta \cdot e^{-\gamma n A^{S} / Z}\left(1-\alpha \cdot e^{-\gamma m A^{Y} / Z}\right),
\end{aligned}
$$

where $0<\beta<1$, and $0<\alpha<1$. Hence, if both stars and young artists' advertising is equal to zero, $1-\beta$ is the fraction of consumers that buy stars' work, $\beta(1-\alpha)$ is the fraction that buy young artists' work, and $\beta \alpha$ is the fraction of consumers that do not buy any artistic work at all.

Stars' profit maximization with respect to marketing expenditures yields the same equilibrium values of $A$ and $a$ as in the main text (see expression (10)). Recall then that, in equilibrium, $A^{S}$ is positive if $n<\gamma \lambda \omega$, which is always satisfied for $\gamma$ sufficiently large. Then, similar calculations yield that young artists' advertising expenditure is positive in equilibrium only if $m=n / \rho<\alpha \beta e^{-\gamma n A^{S} / Z} \gamma \lambda \omega$, which is a much stronger condition (note that $e^{-\gamma n A^{S} / Z}<1$ ). In particular, if $\rho$ is sufficiently small then this condition is never met and, therefore, young artists' advertising is zero in equilibrium. This is the case that we implicitly consider in the main text. In sum, all the qualitative results in the main text remain unchanged if we assume this appendix's expressions for $a^{S}$ and $a^{Y}$, and that $\rho$ is sufficiently small.

\subsection{A general advertising function with individual effects}

In the main text, we assume a specific functional form of the impact of total star advertising $A$ on stars' market share $a$ and we only consider the public good characteristics of stars' advertising. We now generalize this in two directions: we consider a general functional form $a(A)$ and we take into account that each star's advertising has an individual effect on her market share besides the effect on stars' aggregate market share.

The impact of stars' advertising on their aggregate market share is now given by a general function $a(A)$ such that $a(0)>0, \lim _{A \rightarrow \infty} a(A)<1, a^{\prime}(A)>0, a^{\prime \prime}(A)<0$. Note that because $a(A)$ is bounded from above, we also have $\lim _{A \rightarrow \infty} a^{\prime}(A)=0$. Furthermore, we assume that each star's advertising also increases the perceived quality of her individual work. We denote star $i$ 's perceived quality by $Q_{i}^{S}$, which is a function of her own advertising $Q_{i}^{S}=Q\left(A_{i}\right)$, such that $Q(0)>0, Q^{\prime}\left(A_{i}\right)>0, Q^{\prime \prime}\left(A_{i}\right)<0, \lim _{A_{i} \rightarrow \infty} Q^{\prime}\left(A_{i}\right)=0$.

Consider potential deviations of star $i$ from the symmetric SPNE. The marginal consumer who is indifferent between buying star $i$ 's work or her closest neighbors' work in any of the two 
sides of $i$ 's location, satisfies the condition:

$$
Q_{i}^{S}-p_{i}^{s}-\lambda z_{i}=Q^{S}-p^{s}-\lambda\left(\frac{1}{n}-z_{i}\right)
$$

where $Q^{S}$ and $p^{s}$ denote the symmetric SPNE solution. Star $i$ faces the following demand function and present discounted profits: $x_{i}=\frac{a Z}{\lambda}\left(Q_{i}^{S}-Q^{S}+p^{s}-p_{i}+\frac{\lambda}{n}\right)$ and $\pi_{i}=\frac{a Z}{\lambda}\left(p_{i}-c\right)\left(Q_{i}^{S}-Q^{S}+\right.$ $\left.p^{s}-p_{i}+\frac{\lambda}{n}\right) \omega-A_{i}$. Maximizing profits with respect to marketing expenditures, using symmetry and rearranging yields:

$$
n^{2}=\left[\lambda a^{\prime}(A)+Q^{\prime}\left(\frac{A}{n}\right) \cdot n \cdot a(A)\right] \cdot Z \omega
$$

This expression implicitly defines a mapping from $A \in[0, \infty)$ to $n^{2}$, which we denote as $n^{2}=$ $f(A)$. Note that $f(0)>0$ and that $\lim _{A \rightarrow \infty} f(A)=0$ as depicted in Figure 4 . To see that $\lim _{A \rightarrow \infty} f(A)=0$ note first that $\lim _{A \rightarrow \infty} Q^{\prime}(A / n)=0$ (note that the opposite would imply that $n$ is unbounded so that $\lim _{A \rightarrow \infty} f(A)=\infty$, which then leads to a contradiction because $Q^{\prime}\left(A_{i}\right)$ is bounded by $\left.Q^{\prime}(0)\right)$. Then, $\lim _{A \rightarrow \infty} a^{\prime}(A)=\lim _{A \rightarrow \infty} Q^{\prime}(A / n)=0$ in expression (29) implies $\lim _{A \rightarrow \infty} f(A)=0$.

Furthermore, an increase in $\omega$ shifts the $f(A)$ schedule to the right as long as $d A / d \omega>0$ in (29). There are intuitive conditions that ensure this. For instance, this occurs if the elasticity of $a$ with respect to $A$ is no larger than $1\left(a^{\prime} \frac{A}{a} \leq 1\right)$ and the absolute value of the curvature of $Q$ is at least equal to $1\left(-\frac{Q^{\prime \prime}\left(A_{i}\right)}{Q^{\prime}\left(A_{i}\right)} A_{i} \geq 1\right)$ (hence the impact of advertising is limited and decreasing). This can be checked by differentiating (29) with respect to $A$ and $\omega$, which yields:

$$
\frac{d A}{d \omega}=-\frac{\lambda a^{\prime}+Q^{\prime} n a}{\lambda a^{\prime \prime}+Q^{\prime \prime} a+Q^{\prime} n a^{\prime}} \frac{1}{\omega}=-\frac{\lambda a^{\prime}+Q^{\prime} n a}{\left(a^{\prime \prime} A / a^{\prime}\right)\left(\lambda / Q^{\prime} n A\right)+\left(Q^{\prime \prime} A_{i} / Q^{\prime}\right)\left(a / a^{\prime} A\right)+1} \frac{A}{\omega} \frac{1}{n Q^{\prime} a^{\prime}} .
$$

Now, consider the free-entry condition in the young artists sub-market $(1-a(A)) Z \lambda \rho^{2} / n^{2}-$ $F^{Y}=0$ and $n=\rho m$, which yield

$$
n^{2}=\frac{(1-a(A)) Z \lambda \rho^{2}}{F^{Y}}
$$

This expression defines a mapping from $A \in[0, \infty)$ to $n^{2}$, which we denote as $n^{2}=g(A)$. Note that $g(A)^{\prime}<0$ and that $\lim _{A \rightarrow \infty} a(A)<1$ implies $\lim _{A \rightarrow \infty} g(A)>0$. Moreover, for $\rho$ small enough we have $f(0)>g(0)$. Hence $f(0)$ and $g(0)$ always cross at least once in the positive orthant, with $f(0)$ coming from above. See Figure 4. This determines the equilibrium values $n^{*}$ and $A^{*}$. Moreover, it is easy to see that if the equilibrium is unique, it is stable; and if there is more than one equilibrium, then those with $f^{\prime}\left(A^{*}\right)<g^{\prime}\left(A^{*}\right)$ are the stable ones.

Finally, an increase in $\omega$ shifts the $f(A)$ schedule to the right and therefore reduces $n^{*}$ and increases $A^{*}$ in the single equilibrium if there is only one, or in any of the stable equilibria if there is more than one. This generalizes the result in Proposition 2. 


\section{Appendix D: The copyright term that maximizes creation ver- sus the one that maximizes social welfare}

According to the standard analysis, longer copyrights always increase artistic creation. As already noted, this is not the case in the present model. In fact, we can have $\omega^{W}>\omega^{N}$ as well as $\omega^{W}>\omega^{N}$. To see this, consider the conditions that ensure single global maximizers of senior artistic creation and welfare $\omega^{N}$ and $\omega^{W}$, respectively. Note that at $\omega^{N}$ we have $\epsilon_{N \omega}=0$. Substituting with this into (28) and taking into account that in this case we have $\frac{d A}{d \omega} \frac{\omega}{Z}=\frac{1}{\gamma N}$, yields:

$$
\begin{aligned}
\frac{d W}{d \omega} \frac{\omega}{Z}= & \frac{Q^{S}-Q^{Y}}{\lambda} \frac{N}{\gamma \omega}-\frac{4 \omega+N}{4 \gamma \omega N} \\
& +\frac{1}{2}\left[\frac{N}{\gamma \omega Z}\right]^{1 / 2}\left[\frac{5}{4}\left(F^{Y}\right)^{1 / 2}+\rho \frac{F^{S}}{\left(F^{Y}\right)^{1 / 2}}-\frac{F^{S}}{k} \frac{1}{\left(\frac{Z}{\gamma \omega N}\right)^{1 / 2}-\left(F^{Y}\right)^{1 / 2}}\right] .
\end{aligned}
$$

Recall that in equilibrium we have $\frac{Z}{\gamma \omega N}>F^{Y}$ and that $\gamma$ is always assumed to be large with respect to $N$ and $\omega$. Thus, this derivative can be both positive and negative. Specifically, if the quality difference $Q^{S}-Q^{Y}$ is sufficiently large, or if the preference for diversity $\lambda$ or stars' opportunity costs $F^{S}$ are sufficiently small, then this derivative is positive. This would imply $\omega^{W}>\omega^{N}$. Conversely, under the opposite conditions this derivative is negative, implying $\omega^{W}<\omega^{N}$. Interestingly, the potential reasons to depart from the creation-maximizing copyright length $\omega^{N}$ are very different in the two cases. In the case $\omega^{W}>\omega^{N}$, the reinforcement of copyrights beyond $\omega^{N}$ is aimed at raising the consumption of the stars' high-quality creations. In the case $\omega^{W}<\omega^{N}$, it is socially beneficial to shorten copyright protection below $\omega^{N}$ in order to reduce expensive entry of mediocre senior artists that have relatively low productivity and quality. 


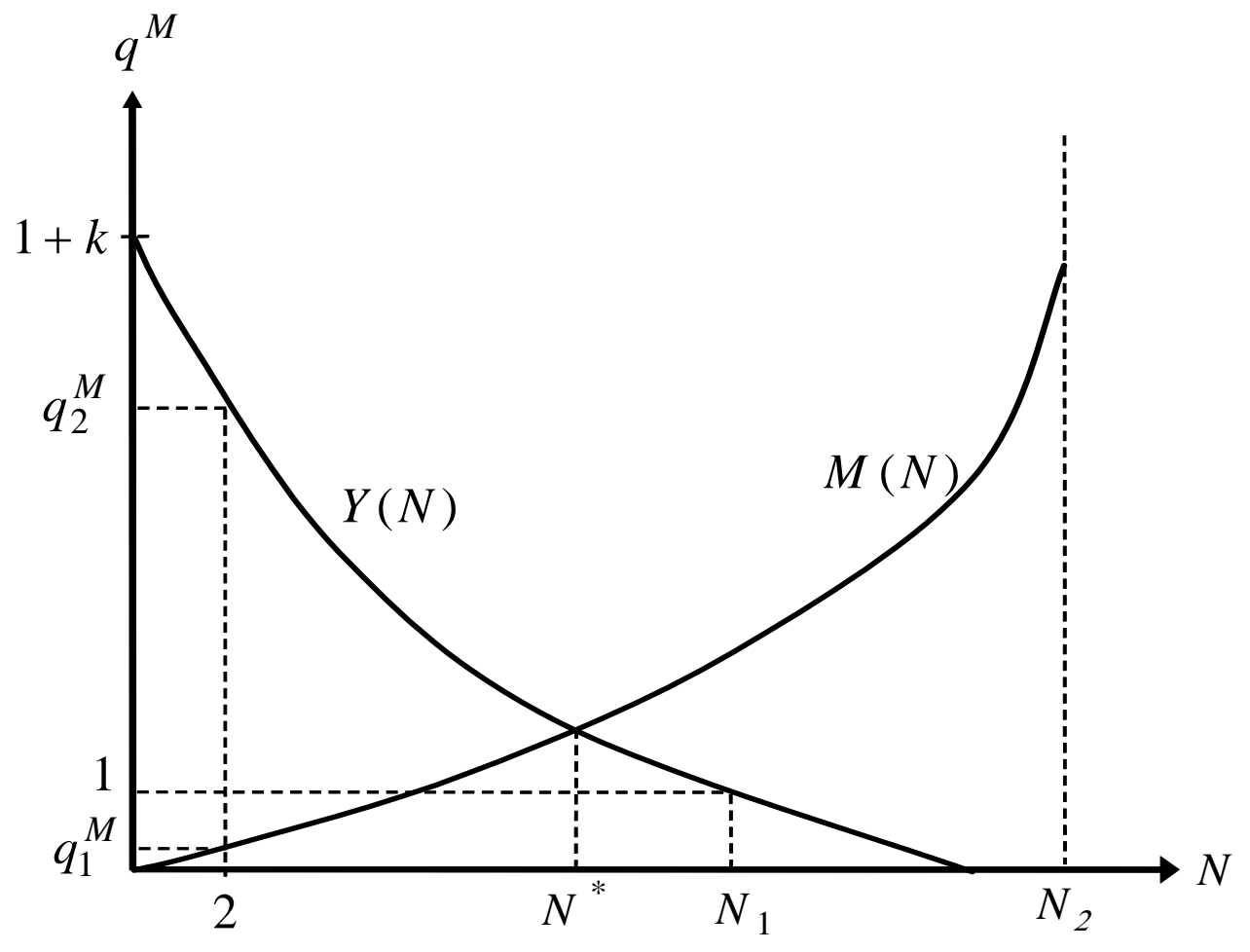

Figure 1: Equilibrium in the model with a continuum of talents.

Extending the copyright term $(\omega)$ shifts downwards both the $M(N)$ and the $Y(N)$ schedules. This reduces the marginal artist's talent $q^{M}$. Furthermore, if the artistic market has a strong superstar configuration (large $k$ ), the shift in $Y(N)$ dominates and reduces senior artistic creation in the long run $\left(N^{*}\right)$. 


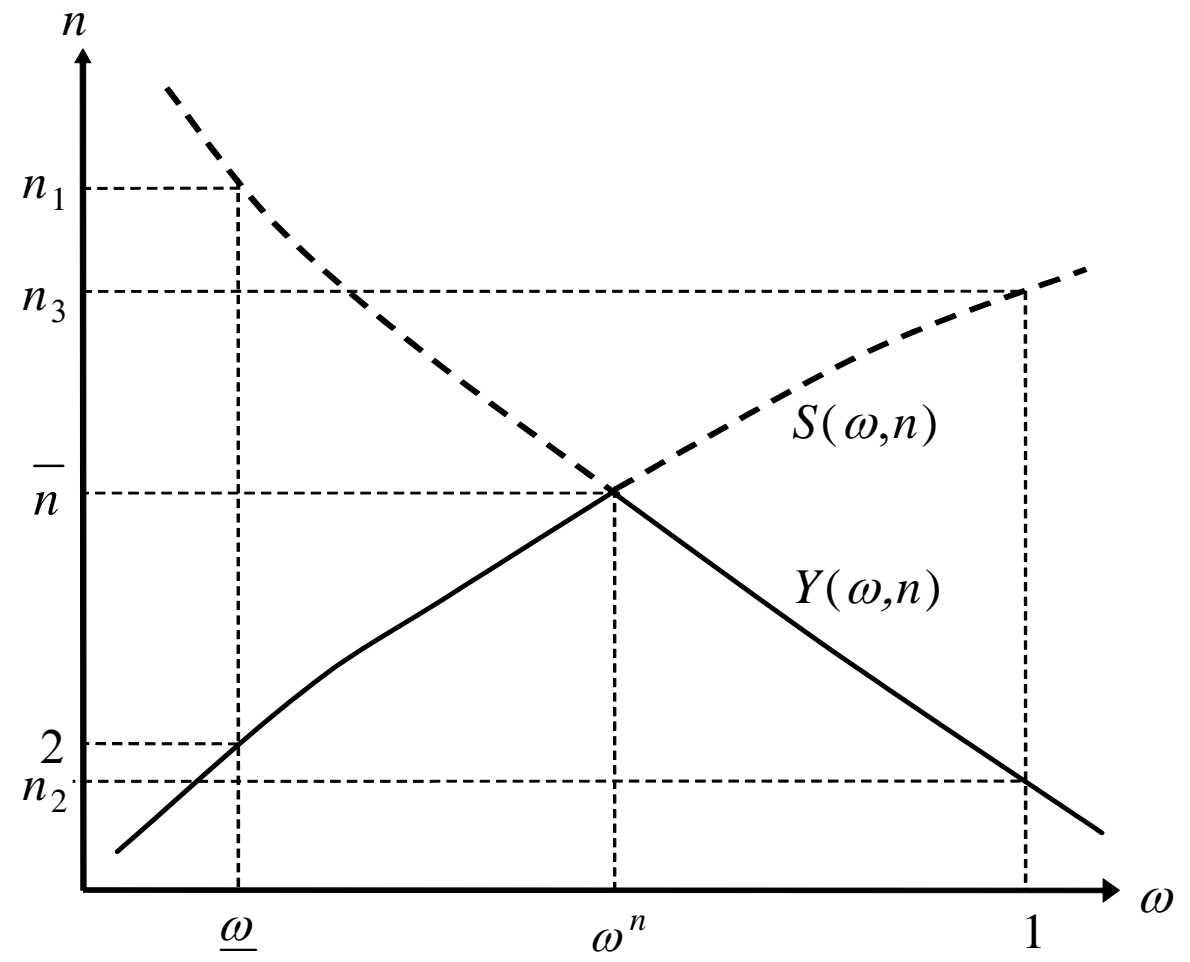

Figure 2: The long-run number of talented senior artists (stars) ( $n$ ) and the copyright term $(\omega)$ in the two artist types model with $\theta>0$. Stars' income is equal (or higher) than their opportunity costs for points in (or below) $S(n, \omega)$. Young artists' expected discounted returns of beginning an artistic career are equal (or higher) than their opportunity costs for points in (or below) $Y(n, \omega)$. The solid line shows the long-run number of stars as a function of the length of the copyright term. 


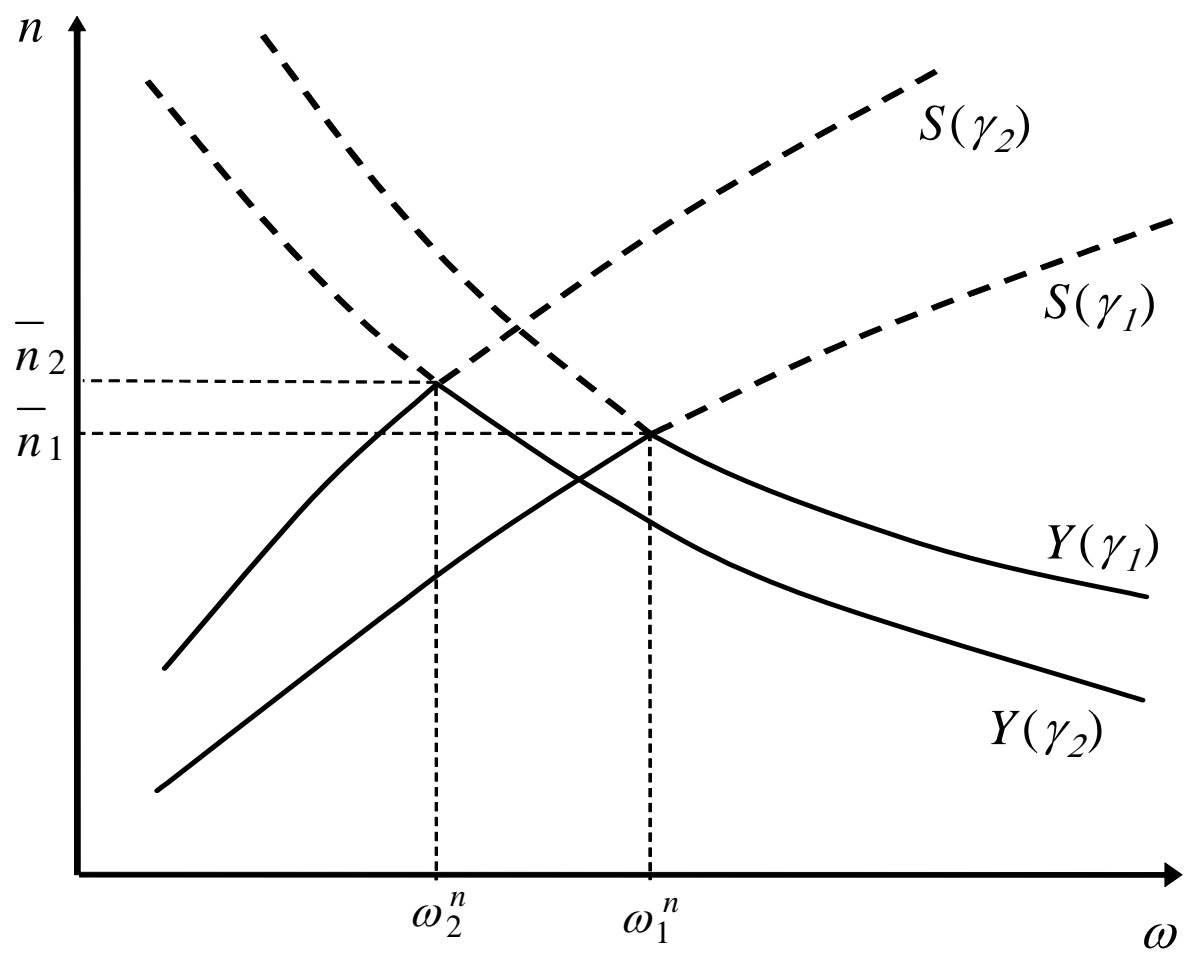

Figure 3: The long-run number of stars $(n)$ and the copyright term $(\omega)$ in the two artist types model with $\theta>0$. Improvements in communication and marketing technologies as well as reductions in the barriers to the globalization of culture are captured by increases in $\gamma$. They shift upwards the $S(n, \omega)$ schedule and downwards the $Y(n, \omega)$ schedule. The solid lines show the long-run number of stars $n$ as a function of the copyright term $\omega$. 


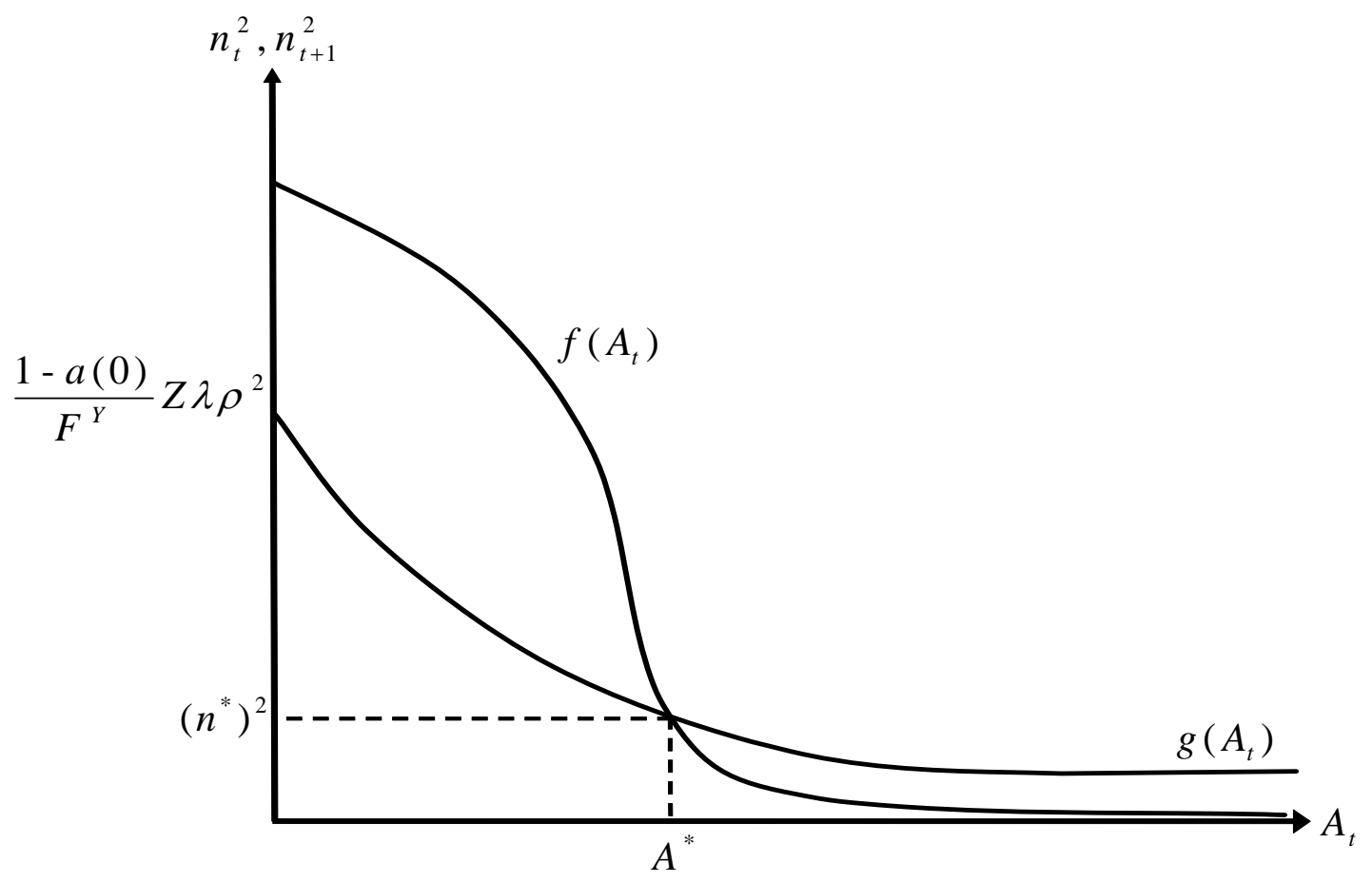

Figure 4: Equilibrium with a general advertising function having individual effects. Extending the copyright term $\omega$ shifts the $f(A)$ schedule to the right, thereby increasing advertising $A^{*}$ and reducing the long run number of stars $n^{*}$. 